\title{
Industrial Cluster Formation As A Strategy To Diversify A Sub-National Economy: Illustrations From South Africa's North West Province
}

\author{
Noleen Pisa North-West University, Potchefstroom Campus, South Africa \\ Riaan Rossouw, North-West University, Potchefstroom Campus, South Africa \\ Wilma Viviers, North-West University, Potchefstroom Campus, South Africa
}

\begin{abstract}
Economic modelling techniques can assist policy makers to understand the effects of policy or external shocks and to make informed decisions about economic development programmes. Economic diversification is a priority of resource-dependent regions such as South Africa's North West Province (NWP) in the wake of the 2014 platinum strike. The economy of the NWP is highly specialised and dependent on a few sectors - in particular, mining and quarrying. Both the NWP and the South African economies were adversely affected by a prolonged strike in the platinum sector. This paper sets out to illustrate the effects of industrial cluster formation as a strategy to enhance competitiveness in the NWP and diversify its economy using SAM multiplier analysis. The supported activity of eight of the ten industrial clusters was shown to be greater than the actual activity, indicating that industrial cluster formation will enhance economic activity in the NWP. Of the ten identified clusters for the NWP, four were found to be moderately integrated and to have high upstream effects. Finally, structural change in the NWP economy through industrial cluster formation was observed using economic landscaping. A key finding was that the identified industrial clusters are significant contributors to the structural change of the NWP economic landscape with the promotion of cluster-specific exports. It is recommended that the North West provincial government adopt this strategy with a view to enhancing competitiveness and economic diversification.
\end{abstract}

Keywords: Industrial Clusters; Economic Diversification; Competitiveness; Multipliers

\section{INTRODUCTION}

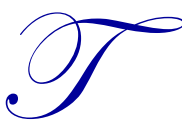

he need for policy makers to understand the sectoral, regional, temporal and social effects of policy or external shocks has been a key driver in the advances made in economic modelling to address this challenge. Economists have come up with a number of methods that can assist national and regional governments to make informed decisions about economic development programmes (Honkatukia, 2013). In this regard, social accounting matrices (SAMs) can be useful in calibrating a broad class of models to demonstrate the social and economic effects of different policies.

The economy of the North West province (NWP) of South Africa is highly specialised and dependent on a few sectors (Pisa, 2014). This dependency manifests in particular in the following four sectors: mining and quarrying (25.5\%), financial services (16.7\%), government services (13.9\%), and trade and accommodation (11.4\%). Together these contributed 67.5\% of the NWP's output in 2011 (Quantec Easy Data, 2014). Its heavy reliance on resources (i.e. mining and quarrying) makes the province vulnerable to external shocks and currency fluctuations. Furthermore, resource dependency makes the provincial economy prone to macroeconomic instability and crowds out domestic industry, including manufacturing (Eitzen, 2012). Manufacturing is crucial for sustainable 
economic development, yet specialisation in resources results in manufacturing losing ground when it comes to development (Kingstone, 2012). In 2014 the NWP and South African economies were adversely affected by a prolonged strike in the platinum mining sector. The strike adversely affected global supply of minerals and mineral products, South Africa's economic growth, mining companies' revenues and workers' remuneration (Singh, 2014; Solomons; 2014; Alers, 2014). Economic activity and economic growth in South Africa contracted in the first quarter of 2014 with real gross domestic product (GDP) declining to $-0.6 \%$, in the first quarter of 2014 compared to $3.8 \%$ in the last quarter of 2013 (SARB, 2014). Mining production decreased by $6.5 \%$ year-on-year in May 2014 (SARB, 2014). In terms of platinum supply, 440000 ounces of platinum production was lost. The three major companies in the sector; Impala Platinum, Amplats and Lonmin suffered a total revenue loss of about R24.1billion during the strike while the workers incurred a further loss of R10.6 billion in wages (Platinum Wage Negotiations, 2015).

In the wake of the 2014 platinum sector strike it is crucial for the NWP to implement strategies to diversify its economy and to minimise the adverse effects of dependence on mineral resources. To address this problem, this paper proposes an industrial cluster formation strategy and illustrates how it can help to enhance competitiveness and diversify the economy of the NWP. To achieve this, the Structural Path Analysis (SPA) and Power-of-Pull (PoP) methods were applied to a 2006 provincial Social Accounting Matrix (SAM) for the NWP in order to identify industrial clusters (Pisa, 2014). This paper shows industrial cluster formation's contributions to the NWP economy using detailed analysis to illustrate how the clusters interact with other sectors and to trace their impact throughout the economy. An important aspect of this study is to estimate the economic contributions of industrial clusters to the NWP economy. Specifically, the paper focuses on the use of the NWP SAM to develop simple economy-wide multipliers and economic landscaping. These two methods respectively, illustrate the effects of industrial cluster formation on the NWP's economy by demonstrating the additional output, employment, employment income and GDP that each cluster can generate as well as the change in the structure of the economy of the NWP.

The rest of this paper is structured as follows: section 2 (below) provides a background on multiplier analysis as a tool to measure the strength of interactions among sectors. Section 3 discusses the methods used and section 4 presents the results, which comprise: the graphical presentation of the clusters' backward and forward linkages, the supported activity generated by the ten identified clusters, and the economic landscapes of the NWP economy pre- and post-industrial cluster formation. Section 5 concludes the paper with some final observations.

\section{THE USE OF MULTIPLIER ANALYSIS TO MEASURE THE STRENGTH OF INTERACTIONS AMONG SECTORS}

The level of activity directly associated with a sector differs from the level of activity that the sector supports. According to Learmonth, Munrow \& Swales (2003), the supported activity of clusters is expected to be higher than the direct activity due to the enhanced competitiveness of clusters. Porter's view on the genesis and evolution of industrial clusters supports this notion. According to Porter (2002), the establishment of firms and subsequently clusters in response to the availability of factors of competitiveness in a region leads to the creation of a competitive industry. The success of an industry makes it a sophisticated buyer of products and services (Porter, 2002). Both domestic and foreign suppliers will be attracted to establish operations in close proximity to this competitive industry in order to provide goods and services, which in turn increases the cluster's supported output.

The SAM provides a basis for measuring the strength of interaction among sectors (Czamanski, 1974). This is achieved by analysing multipliers. Multipliers measure the forward and backward, as well as the direct and the indirect, linkages that exist between the cluster sectors themselves and between cluster and non-cluster sectors (Learmonth et al., 2003). SAM multiplier analysis can be traced back to the 1970s, with studies such as those of Pyatt and Thorbecke (1976), Pyatt and Round (1979), Hayden and Round (1982), and Defourny and Thorbecke (1984). These studies mainly analysed the effects of government policy to reduce poverty and inequality by observing household and income multipliers. A SAM shows the circular flow of income in an economy in a square matrix format (Ciaschini \& Socci, 2007). The underlying structure of a SAM includes structural and/or behavioural specifications for the various groups of transactions (Round, 2003). In particular, the SAM specifies the structural changes of relative prices. SAM multipliers account not only for the direct and indirect effects but also for the induced effects on factor and household incomes and activity outputs due to the (Keynesian) income-expenditure 
multipliers (Robinson, 1989; Adelman \& Robinson, 1989). SAM multiplier analysis gives some indication of the possible resultant effects of an exogenous shock on the functional (factoral) and institutional distributions of income as well as on the structure of output.

Traditional multiplier analysis or "first cut ex-ante analysis" in a SAM captures the generation of income by activities by producing commodities. It maps the income payments to the different factors of production, the distribution of factor and non-factor income payments to households, and the subsequent spending of income by households on commodities (Round, 2003; Breisinger, Thomas \& Thurlow, 2010). These patterns of payments are manifested in the structural features and interdependencies of the SAM. The patterns of payments are modelled analogously to the input structure of the activities in a SAM model, based only on inter-industry transactions for that particular economy (Round, 2003). Traditional multiplier analysis gives some indication of the contributions of each sector to various indicators, such as production, value added, capital and labour, relative to the structure of the economy. Traditional SAM multipliers measure the effects of production linkages only.

There are 4 types of multipliers that can be computed. Type I multipliers constitute direct and indirect output changes to the initial direct change in final demand (Learmonth et al., 2003). Miller and Blair (1985) define Type II multipliers as the ratio of the direct, indirect and (income) induced changes associated with a direct change in a given sector. This means that Type II multipliers account for induced impacts based on the purchases made by employees in addition to the direct and indirect impacts (Bess \& Ambargis, 2011). Lee (1986) states that Type III multipliers involve the inclusion of another final demand component, such as state and local government expenditure, as an endogenous account. Type IV multipliers (income and employment multipliers) can be obtained by pre-multiplying the matrix of output multipliers by a row vector of wage-to-output ratios in the case of income, and employment-to-output ratio in the case of employment (Ciaschini \& Socci, 2007; Polenske \& Jordan, 1988).

\section{METHODS}

\subsection{Identifying Industrial Clusters Using the SPA and PoP Methods}

Structural path analysis (SPA) was applied to a social accounting matrix for the NWP. The SPA was conducted using the program, SimSIP SAM, which is a Microsoft Excel tool developed by the World Bank that utilises MATLAB to analyse I-O and SAM tables (Parra \& Wodon, 2009). Fixed origin analysis was conducted in SimSIP SAM. SPA decomposes SAM multipliers into direct and indirect components and reveals the network through which transmission occurs (Defourny \& Thorbecke, 1984; Rasmussen, 1956; Hirschman, 1958). The backward linkages or diffusion effects are calculated as follows:

$\mathrm{BL}_{j}=\frac{B_{j}}{\frac{1}{n} v}, j=1 \ldots n$

The forward linkages or the absorption effects are calculated as follows:

$\mathrm{FL}_{i}=\frac{B_{i}}{\frac{1}{n} v}, i=1 \ldots n$

Where $B$ represents the sectorial interdependences in an economy or the Multiplier Product Matrix (MPM). The subindexes i, j make reference respectively to the rows and columns of the corresponding matrices. $n$ is the number of endogenous variables in the SAM that is, the productive sectors, the production factors and the consumers. $v$ is a global intensity factor that corresponds with the sum of all the elements of the associate inverse matrix. If the backward linkages are greater than 1, it implies that a unit change in the final demand of sector $j$ will generate an increase above the average in the global activity of the economy (Lima, Cardenete \& Vallés Ferrer, 2005). If the forward linkages are greater than 1 , it implies that a unit change in all the sectors of the final demand will generate an increment above the average in sector $i$. A key sector is the one with both indexes greater than 1 (Lima et al., 2005). 
The SPA method, however, does not determine the optimal number of clusters. It shows different clusters and how they are interconnected with the rest of the economy, but it does not show the most important cluster with the greatest economy-wide effects. In light of this, the power-of-pull ( $\mathrm{PoP}$ ) method was used to prioritise the number of clusters. This is essential for the effective promotion of industrial clusters because governments have limited resources (Martin \& Sunley, 2003). Following Dietzenbacher (1992), we assume $\mathbf{r}_{i}$ to be a vector of power indicators of the sectors, and the indicator vector $\mathrm{r}_{i+1}$ is updated as the sum of backward linkages (columns of the $\mathrm{A}$ matrix) weighed by the normalised $r_{i}$ from the previous iteration. The inputs from a sector with high pulling power receive a larger weight than the inputs from a sector with lower pulling power. The power scores, which are also used as the weighting factors, are normalised to have an average of 1 . The power scores take the following form:

$r_{i+1}=n \grave{r}_{l} A / \grave{r}_{l} A e$

Where $n$ is the total number of sectors, and $e$ is the column summation vector ( $e_{i}=1$ for all $i$ ). Estimates of a sector's power indicator improve through iterations to infinitum $(i \rightarrow \infty)$. Furthermore, according to Dietzenbacher (1992), "the indicator converges to the normalised left hand eigenvector corresponding to the dominant eigenvalue (i.e. the Perron vector) of the input coefficient matrix A". The indicator vector can be calculated as $n q^{\prime} /\left(q^{\prime}\right)$ with:

$\dot{q}=\lambda \dot{q}$

Where $\mathrm{q}^{\prime}$ is the dominant eigenvalue of the A matrix. The elements of $n \mathrm{q}^{\prime} /\left(\mathrm{q}^{\prime} \mathrm{e}\right)$ indicate how powerfully the activities of sectors may pull the activities (thus outputs) of the overall economic network (including themselves), i.e. the power-of-pull. For more details on this method, including its derivation, see Dietzenbacher (1992).

\subsection{Illustrating the Effects of Industrial Cluster Formation on the NWP Economy}

\subsubsection{Graphical Representation of Multiplier Analysis}

Following Learmonth et al. (2003) the linkages a cluster has with the rest of the economy are identified using an accounting procedure that quantifies the intermediate purchases made by that sector (both direct and indirect). This proposed method has been discussed in detail by Learmonth et al. (2003) and can be illustrated using an example. The production of the agriculture cluster sector output (commodities) as an example requires intermediate production inputs. The intermediate inputs, in turn, require intermediate inputs ad infinitum, thereby generating a multiplier process. With cluster formation agriculture output will increase, but in order for these increases to occur the agriculture cluster sector's demand for intermediate production inputs will increase. The intermediate inputs' demand for intermediate inputs will in turn increase ad infinitum resulting in the increase in economic activity of other sectors in the economy and the diversification of economic activity from mining. Therefore it is essential to understand how well the identified industrial clusters are interlinked with the different sectors in the NWP. With the identification of the clusters' inter-industry strengths to the different economic sectors, the economic sectors related to the clusters can be better informed of the opportunities that cluster formation presents.

The SAM provides a basis for measuring the strength of interaction among sectors (Czamanski, 1974). This is achieved by analysing multipliers. Multipliers measure the forward and backward as well as the direct and the indirect linkages that exist between the cluster sectors themselves and between cluster and non-cluster sectors (Learmonth, Munrow \& Swales, 2003). Porter (2002) highlighted that downstream industries are drawn to the cluster location to enhance the transmission of information to suppliers about their needs. Type I multipliers are calculated in each case to capture the downstream effects. Type I multipliers incorporate the indirect impacts associated with intermediate purchases (Ciaschini \& Socci, 2007). In order to capture the upstream effects, Type II multipliers are calculated. In addition to capturing the indirect impacts associated with intermediate purchases, Type II multipliers include induced consumption effects on gross output, employment, wage income or value added (Ciaschini \& Socci, 2007). 
The summary multiplier values for the ten identified potential clusters for the NWP are graphically presented. Data from the NWP SAM (particularly the intermediate demand) are used. The full direct and indirect linkages associated with the production of any of the cluster sectors and their associated sectors' outputs are calculated from information embedded in the SAM table (Miller \& Blair, 1985). The main advantage of presenting the linkages between the cluster sectors and the non-cluster sectors in this way is that no information is lost. The graphical presentation provided of the results depicts all the linkages a particular cluster has with the rest of the NWP economy.

\subsubsection{Measuring Supported Activity Induced by Industrial Cluster Formation in the NWP}

Following Learmonth et al. (2003), we applied multiplier analysis together with SAM data to determine each cluster's supported activity, that is additional output, employment, employment income and GDP generated by clusters and to show the impact of each cluster on the economy. The output, employment income and GDP data used were obtained from the 2006 NWP SAM (Conningarth Economists, 2009). The employment numbers used were obtained from Quantec Easy Data (2013). Additionally, employment numbers were measured as full-time equivalents, while the monetary values were measured in 2006 prices. The supported activity was derived using the relevant Type II SAM multipliers applied to the sector's final demand. Supported output is the direct final demand for cluster output. This includes indirect expenditure on intermediate goods directly or indirectly needed to meet final demands. Additionally, supported output includes exports, sales to the government and investment. Type I and Type II multiplier analysis were conducted. Type I multipliers are calculated in each case to capture the downstream effects. Type I multipliers incorporate the indirect impacts associated with intermediate purchases (Ciaschini et al., 2007). This means that under Type I analysis, consumption demand is treated as a final demand in its own right. Contrary to this, in Type II analysis, consumption demand is treated as induced expenditure on consumer goods and services purchased from the wages generated ultimately by the sales to other final demand. Type II multipliers are calculated in order to capture the upstream effects. In addition to capturing the indirect impacts associated with intermediate purchases, Type II multipliers also include induced consumption effects on gross output, employment, wage income or value added (Ciaschini et al., 2007). Resultantly, the sum of supported activity for all sectors in the economy gives sum to the total activity in the economy as a whole.

The level of activity directly associated with a sector differs from the level of activity it supports. According to Learmonth et al. (2003), the supported activity of clusters is expected to be higher than the direct activity owing to the enhanced competitiveness of clusters. Porter's view on the genesis and evolution of industrial clusters supports this notion. According to Porter (2002), the establishment of firms and subsequently clusters in response to the availability of factors of competitiveness in a region leads to the establishment of a competitive industry. The success of an industry makes it a sophisticated buyer of products and services (Porter, 2002). Both domestic and foreign suppliers will be attracted to establish in close proximity to this competitive industry to provide goods and services thereby increasing the cluster's supported output.

\subsubsection{Illustrating the Structural Change of the NWP Economy Induced by Industrial Cluster Formation}

Economic landscaping is used in this study to demonstrate the changes in the structure of the NWP that will be induced by industrial cluster formation. Economic landscaping is derived from the methods of linkage analysis (Sonis, Hewings \& Guo, 2000). This method is based on the multiplier product matrix (MPM) of the SAM. The MPM ranks sectors according to the strength of their linkages with other sectors. This means that the MPM quantifies and ranks the inter-industry linkages between sectors (Parré, Alves \& Sordi, 2002).

The MPM shows an industry's linkages. That is, the MPM reflects the impacts of an industry on other industries or the relationship of an industry to all other industries. These linkages represent the inter-industry exchange of an industry with other industries, both as a producer of output and a consumer of inputs (Guo \& Planting, 2000). An industry's linkages can be compared with those of other industries or with itself at different points in time.

The results of economic landscaping can be illustrated in matrix. The economic landscape shows the hierarchy of backward and forward linkages as well as the structure of an economy (Parra \& Wodon, 2008). In this 
regard, the economic landscape matrix shows the economic sectors' ranking based on the size of their hierarchies of the backward and forward linkages (Bonet, 2005; Khanal, 2011). This reveals the changes in the structure of the economy. The economic landscape matrix enables one to visualise the economic structure in the two different scenarios.

The structural change in the economy of the NWP was depicted using SimSIP SAM. In this paper SimSIP SAM was used to model the economic landscape of the NWP before industrial cluster formation (as it was in 2006; hereafter referred to as pre-cluster economic landscape). In order to model the effects of industrial cluster formation in the SAM (hereafter referred to as post-cluster economic landscape), exports of the ten identified clusters were increased by $10 \%$. The data for the two scenarios were entered into the SimSIP SAM software to generate the results. The economic landscapes of the NWP generated pre- and post- industrial cluster formation are depicted as heat maps. Since the NWP SAM comprises 37 sectors, heat maps of the MPMs allow a better visualisation of the increases and decreases in backward and forward linkages associated with the promotion of cluster-specific exports.

\section{RESULTS}

Ten industrial clusters were identified and prioritised for the NWP. These ten clusters are:

(i) Communication

(ii) Real estate

(iii) Grain mill, bakery and animal feed products

(iv) Building and other construction

(v) Basic metal products

(vi) Other food products

(vii) Agriculture

(viii) Non-metallic mineral products

(ix) Trade

(x) Dairy products (Pisa, 2014).

The clusters are ranked according to PoP scores. A cluster's or sector's PoP is its power to pull (influence) all sectors through direct and indirect linkages in the network (Newman, 2008). As a result, the ranking of clusters by PoP reflects each cluster's strength (power to pull other sectors). The subsequent section illustrates inter-linkages of the identified industrial clusters with the different sectors in the NWP. This is helps to illustrate the impact that the identified clusters will have on the NWP economy through inter-linkages with other sectors.

\subsection{Illustrating the Levels of Integration and the Supported Activity of the NWP's Clusters}

To add further insight into the benefits of each identified cluster, the following subsections also provide a graphical illustration of the multiplier effect of each cluster. The figures represent three variables for each of the sectors in each cluster, namely upstream effects, downstream effects and scale. The sum of the upstream linkages of a particular cluster sector represents its utilisation of the value added of all other sectors' outputs as intermediate inputs. Additionally, in monetary terms, this represents "the proportionate reduction in costs in an individual cluster sector caused by the lowering of intermediate input prices if the value added of all cluster sectors could be produced at zero cost" (Learmonth et al., 2003:579). A high upstream effect score means that the sector utilises a large amount of intermediate inputs from other sectors in the NWP economy.

The downstream effects represent the proportion of a sector's gross output that is utilised directly or indirectly as an intermediate input (final demand) by other sectors in the economy. In monetary terms, the downstream effect measures "the proportionate reduction in the output of a particular cluster caused as a result of reduced intermediate demand if the final demands for the output of all cluster sectors fell to zero" (Learmonth et al., 2003:579). A high downstream effect score means that a sector has high intermediate sales to other sectors. Downstream and upstream effects are measured on a scale of 0 and 100 percent, respectively. The upstream effects for individual sectors are shown on the $\mathrm{x}$-axis, and the downstream effects on the $\mathrm{y}$-axis. 
Scale is measured as the size of the sector's value-added in the NWP SAM. The scale is shown by the size (area) of the bubble in the figures. There is no direct association between the scale and the upstream and downstream effects, respectively. Sectors towards the top right corner of the diagram are ones that have the highest relative backward and forward linkages. A strong cluster may be represented by an image with many sectors in the top right corner of the bubble chart, indicating an integrated set of sectors that are reliant on each other's value added and final demands. The graphical presentation of the multiplier analysis illustrates the strength of existing linkages in each of the ten clusters. This highlights the level of integration (dependency of sectors) that exists between the sectors in each of the clusters. A strong cluster may be represented by an image with many sectors in the top right corner of the bubble chart, indicating an integrated set of sectors that are reliant on each other's value added and final demands.

While the graphical presentation of the multiplier analysis illustrates the strength of existing linkages in each of the ten clusters, which highlights the level of integration (dependency of sectors) that exists between the sectors in each of the clusters, we also present the results of applying multiplier analysis for the ten identified potential clusters. The aim is to show the impact of each cluster on the NWP economy, in particular on output, employment, employment income and GDP. The monetary values are measured in 2006 prices. The supported activity is derived using the relevant Type II SAM multipliers applied to the sector's final demand.

\subsubsection{Communication Cluster}

In the communication cluster (see Figure 1), the electricity sector has high upstream linkages, although the sector is relatively small (i.e. as seen by the relative size of the bubble). The trade sector is the largest sector in the cluster and has high downstream linkages. The real estate, and building and other construction ('building etc.') sectors also have high downstream effects, though much lower than the trade sector. Similarly, the communication and transport sectors have high upstream effects relative to the electricity sector. The linkages between the other sectors are relatively weak. Figure 1 illustrates that most sectors are located in the bottom left section of the charts, indicating that the cluster has relatively low upstream and downstream linkages. 
Figure 1. Upstream and downstream linkage effects of the NWP communication cluster and related sectors

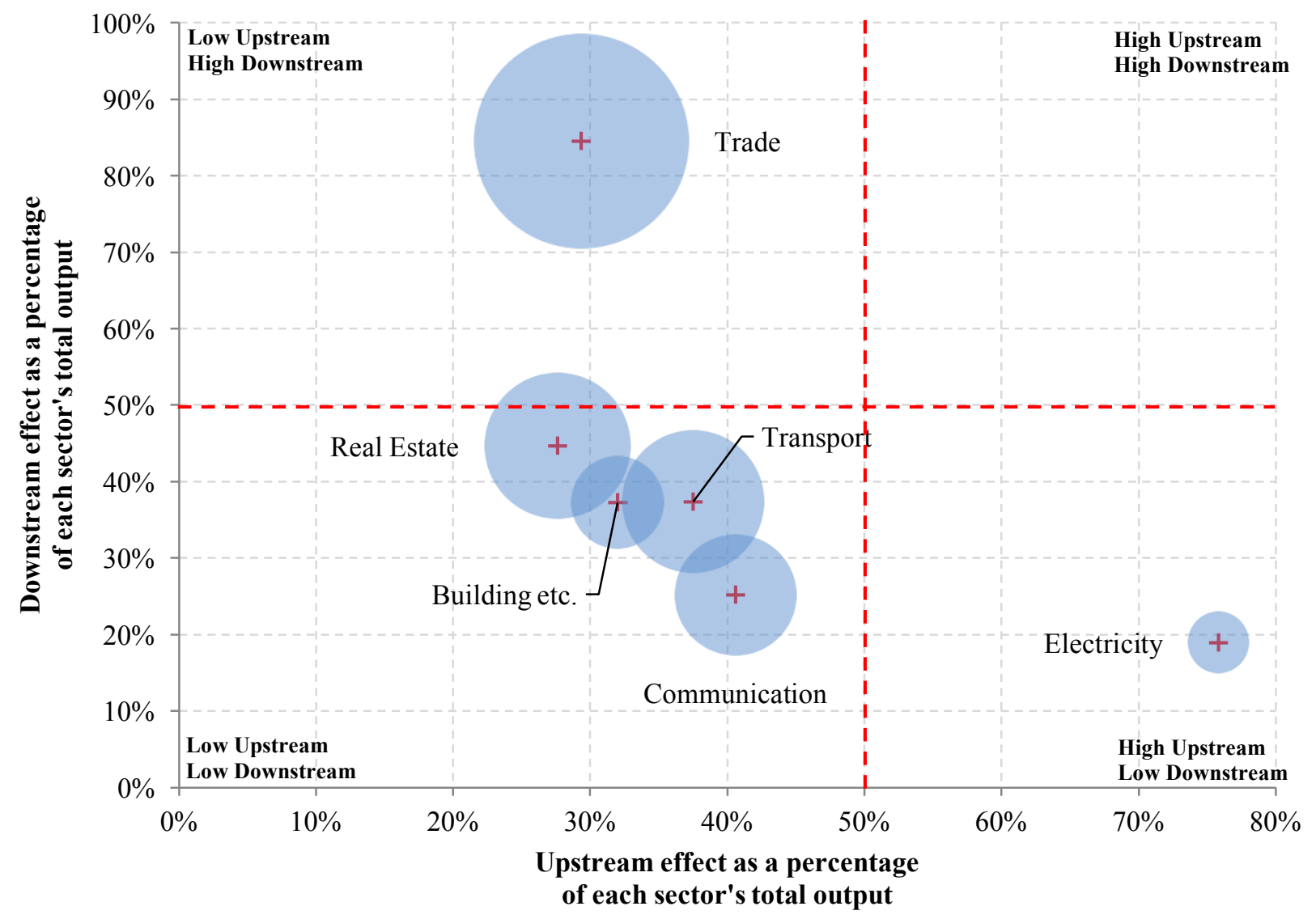

Source: Compiled by authors from Conningarth Economists SAM, 2009

Table 1 shows the NWP's output, employment, income and GDP supported by the communication services industry cluster. The supported activity by the communication cluster is much higher than the actual activity. For example, the communication services cluster will stimulate additional output of $18 \%$ and increase employment by $44 \%$. Employment income in the communication cluster will increase by a significant $172 \%$ as a result of cluster formation. GDP will increase by $26 \%$ from ZAR3.4 billion to ZAR4.3 billion.

Table 1. NWP output, employment, income and GDP supported by the communication services industry cluster

\begin{tabular}{lcccc}
\hline & $\begin{array}{c}\text { Output } \\
\text { (ZAR millions) }\end{array}$ & $\begin{array}{c}\text { Employment } \\
\text { (Number) }\end{array}$ & $\begin{array}{c}\text { Employment income } \\
\text { (ZAR millions) }\end{array}$ & $\begin{array}{c}\text { GDP } \\
\text { (ZAR millions) }\end{array}$ \\
\hline Actual & 8.456 & 13161 & 1.305 & 3.410 \\
Supported & 9.954 & 23455 & 3.549 & 4.295 \\
\hline
\end{tabular}

Source: Conningarth Economists, 2009 and Quantec Easy Data, 2014

\subsubsection{Real Estate Cluster}

Figure 2 shows the upstream and downstream linkage effects of the NWP real estate cluster and related sectors. The business services sector and the community, social and personal services ('CSPS') sector have the highest upstream effects, respectively. Additionally, the trade sector has high downstream effects. Similar to the communication cluster, the real estate cluster is not highly integrated and the sectors in this cluster are not reliant on each other's value added and final demands. This is shown by the low levels of upstream and downstream effects of the sectors in this cluster (most sectors are located in the lower left corner of Figure 2). 
Figure 2. Upstream and downstream linkage effects of the NWP real estate cluster and related sectors

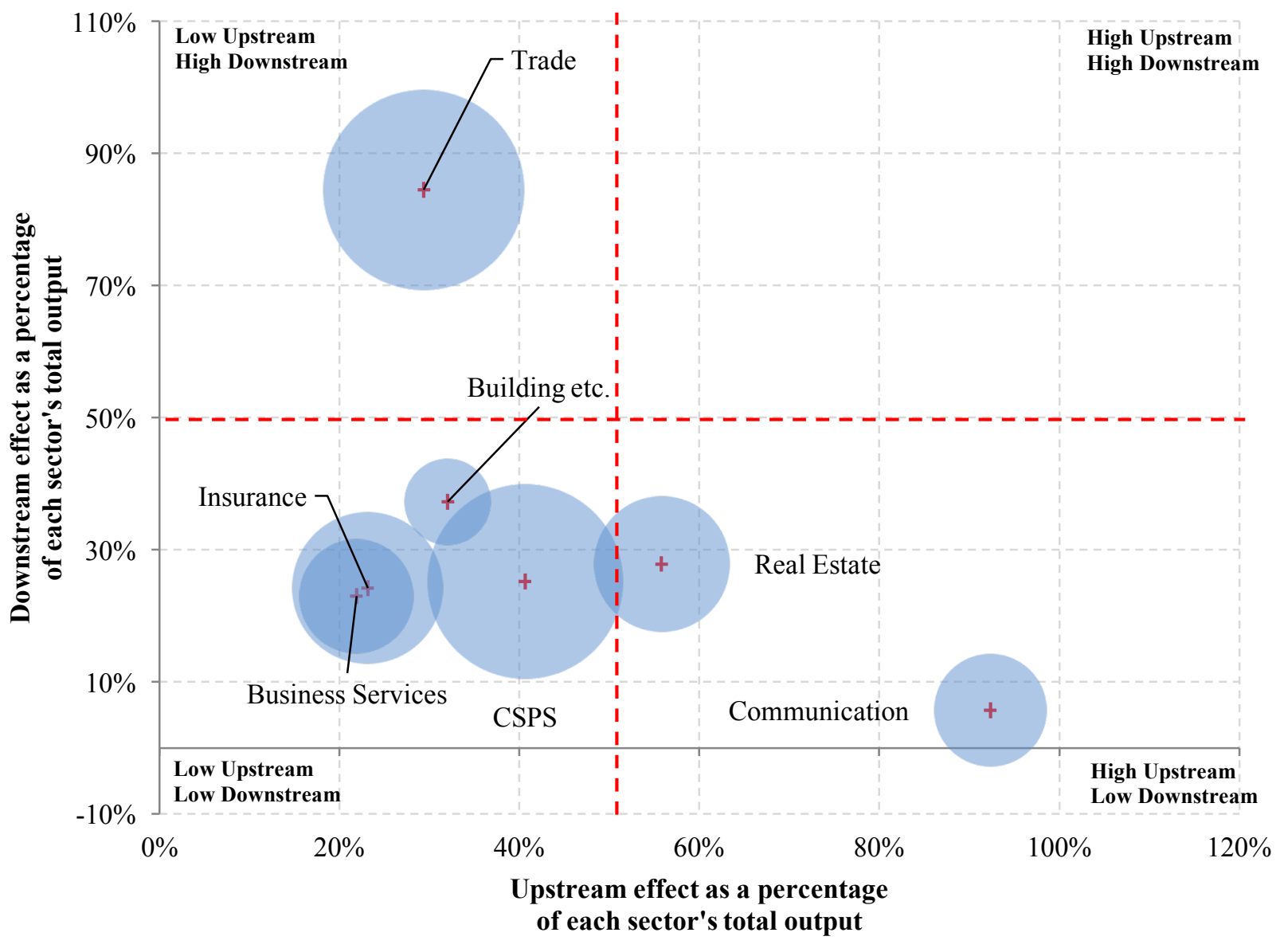

Source: Compiled by authors from Conningarth Economists SAM, 2009

The supported output, employment, income and GDP for the real estate cluster are shown in Table 2. The supported output and GDP for the real estate cluster are much lower than the actual figures. The number of people employed in the cluster will increase from 12657 to 40 251. In addition, employment income is expected to more than treble (240\%) with cluster formation.

Table 2. NWP output, employment, income and GDP supported by the real estate services industry cluster

\begin{tabular}{lcccc}
\hline & $\begin{array}{c}\text { Output } \\
\text { (ZAR millions) }\end{array}$ & $\begin{array}{c}\text { Employment } \\
\text { (Number) }\end{array}$ & $\begin{array}{c}\text { Employment income } \\
\text { (ZAR millions) }\end{array}$ & $\begin{array}{c}\text { GDP } \\
\text { (ZAR millions) }\end{array}$ \\
\hline Actual & 16.360 & 12657 & 1.673 & 10.022 \\
Supported & 12315 & 40251 & 5.735 & 5.523 \\
\hline
\end{tabular}

Source: Conningarth Economists, 2009 and Quantec Easy Data, 2014

\subsubsection{Grain Mill, Bakery and Animal Feed Products Cluster}

The grain mill, bakery and animal feed products ('grain mill etc.') cluster comprises several sectors with high upstream and downstream effects. Trade, community, social and personal services ('CSPS') and agriculture, respectively, are the three largest sectors in the grain mill etc. cluster (see Figure 3). The business services sector, chemicals and chemical products sector ('chemicals etc.') have the highest upstream effects in this cluster. The trade and grain mill etc. sectors have the highest downstream effects. This cluster includes the dairy products sector. Although this sector is small, it has high upstream and downstream effects (above 50\%; see Figure 3). Similarly, the community, social and personal services ('CSPS') and agriculture sectors have relatively high upstream and 
downstream effects (close to $50 \%$ ). This shows that this cluster is more integrated and has potential to integrate more with cluster formation.

Figure 3. Upstream and downstream linkage effects

of the NWP grain mill, bakery and animal feed products cluster and related sectors

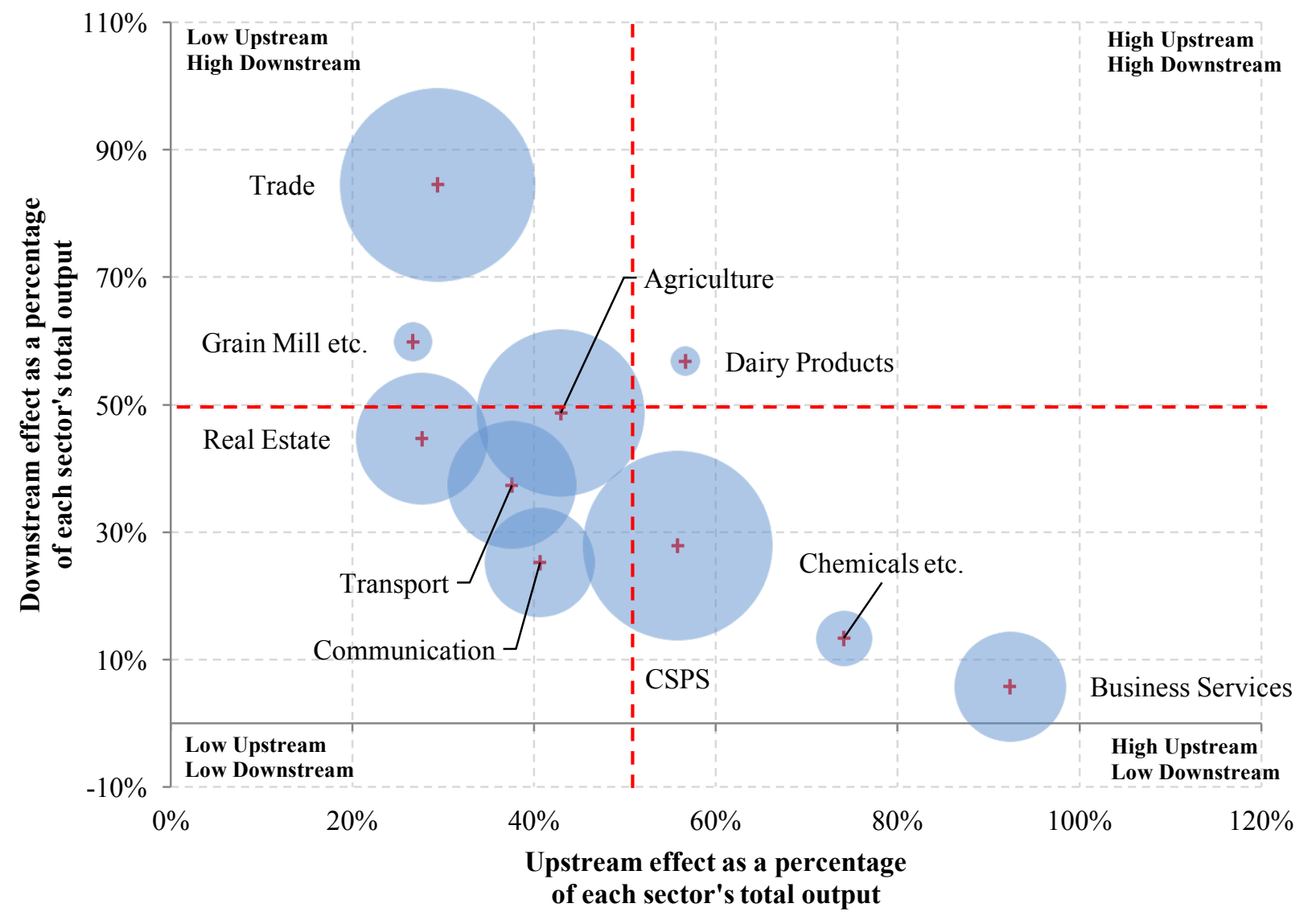

Source: Compiled by authors from Conningarth Economists SAM, 2009

Industrial cluster formation in the grain mill, bakery and animal feed products sector will generate higher levels of economic activity in the NWP. As shown in Table 3, output, employment, employment income and GDP will all increase in response to cluster formation.

Table 3. NWP output, employment, income and GDP supported by the grain mill, bakery and animal feed products industry cluster

\begin{tabular}{lcccc}
\hline & $\begin{array}{c}\text { Output } \\
\text { (ZAR millions) }\end{array}$ & $\begin{array}{c}\text { Employment } \\
\text { (Number) }\end{array}$ & $\begin{array}{c}\text { Employment income } \\
\text { (ZAR millions) }\end{array}$ & $\begin{array}{c}\text { GDP } \\
\text { (ZAR millions) }\end{array}$ \\
\hline Actual & 2.947 & 2916 & 181.44 & 594 \\
Supported & 3.796 & 34032 & 993.66 & 1.650 \\
\hline
\end{tabular}

Source: Conningarth Economists, 2009 and Quantec Easy Data, 2014

The rest of the figures and tables for the proceeding clusters will be presented in Appendices 1 and 2 respectively.

\subsubsection{Building and Other Construction Cluster}

The following sectors have high upstream effects in the building and other construction ('building etc.') cluster: non-metallic mineral products ('non-metallic'), community, social and personal services ('CSPS'), electrical 
machinery ('electrical mach') and structural metals products ('structural etc.') (as shown in Figure 4 in Appendix 1). Only the trade sector has high downstream effects. Efforts to promote industrial cluster formation can enhance the downstream effects in the non-metallic mineral products ('non-metallic'), community, social and personal services ('CSPS'), and electrical machinery ('electrical mach') sectors as they already have high existing upstream effects. This would make the cluster more integrated and would enhance the effects (power-of-pull) of the building and other construction cluster in the NWP economy. All the variables are expected to increase more than the actual values with cluster formation in the building and other construction cluster (see Table 7 in Appendix 2). This highlights that cluster formation will enhance the competitiveness of the building and other construction cluster, resulting in supported activity being greater than the actual activity.

\subsubsection{Basic Metal Products Cluster}

An analysis of the upstream and downstream linkage effects of the NWP basic metal products cluster and related sectors reveals that the other mining sector has low downstream and upstream linkages relative to the other sectors in the cluster (see Figure 5 in Appendix 1). The low downstream effects imply that this sector does not use up a lot of intermediate inputs from other sectors in its production (downstream linkages; $9 \%$ ). Similarly, other mining output is not utilised by many sectors in the NWP as final demand (upstream linkages; 23\%). The following sectors in the basic metal products cluster have high downstream linkages: business services, chemicals and chemical products ('chemicals etc.'), basic metals products ('basic metals etc.') and community, social and personal services ('CSPS'). Output, employment income and GDP in the cluster will increase to support enhanced demand generated by the cluster. The supported employment (number), employment income and GDP in the basic metal products cluster are greater than actual activity (more than $10 \%$ increases; see Table 8).

\subsubsection{Other Food Products Cluster}

The other food products and dairy products sectors are the smallest in this cluster (see Figure 6). However, these two sectors have the highest linkages (both upstream and downstream) with other sectors the NWP economy. Similar to the five clusters discussed thus far, the trade sector is large and has high downstream linkages. Figure 6, however, reveals that most sectors are located in the bottom left section of the charts and as such have relatively low upstream and downstream linkages. Table 9 shows the output, employment income and GDP supported by the other food products industry cluster for the NWP. The other foods cluster will generate higher supported output, employment (number), employment income and GDP for the NWP.

\subsubsection{Agriculture Cluster}

In the agriculture cluster, the chemical and chemical products ('chemicals etc.') sector has high downstream linkages although the sector is relatively small. The trade sector is the largest sector in the cluster (see Figure 7) and has high downstream linkages. The grain mill, bakery and animal feeds ('grain mill etc.') and real estate sectors also have high downstream effects although much lower than the trade sector. Similarly, the community, social and personal services ('CSPS') and dairy products sectors have high upstream effects relative to the electricity sector. The dairy products sector has high upstream and downstream linkages. The machinery and equipment sector has low upstream and downstream linkages. The linkages between the other sectors are relatively weak, as shown by the clustering of the sectors in the lower centre of Figure 7. With cluster formation, output, employment and GDP in the agriculture cluster will decline by $27 \%, 66 \%$ and $40 \%$, respectively (see Table 10). This may be attributed to outsourcing. With cluster formation, firms specialise in activities that they are more efficient in and outsource the rest in order to maintain and enhance cluster competitiveness. Employment income, however, will increase by $70 \%$.

\subsubsection{Non-metallic Mineral Products Cluster}

The non-metallic mineral products cluster in the NWP comprises several sectors that contribute a large portion of the province's value added (see Figure 8). This is shown by the diameter of the bubbles for the different sectors. In terms of upstream linkages, the business services, community, social and personal services ('CSPS') and non-metallic mineral products ('non-metallic') sectors, respectively, have the highest upstream linkages (50\% and 
above). The trade sector has the highest downstream effects in the cluster. However, most of the sectors in the cluster are located in the lower left hand corner of Figure 8. This indicates that the cluster is not highly integrated and that the upstream and downstream linkages between the sectors in the cluster are weak. The non-metallic mineral products cluster will generate more output, employment income and GDP, as shown by the supported activity being larger than the actual activity (see Table 8 ). The number of people employed in the cluster will decline from 16328 to 15971 .

\subsubsection{Trade Cluster}

The trade cluster comprises the highest number of sectors relative to the nine other clusters identified for the NWP. It comprises mostly small sectors. The trade sector itself is the largest in the cluster, while the real estate, transport and communication sectors are relatively large (see Figure 9). Six sectors in the trade cluster have high upstream effects (above 50\%). These are: other fabricated metals ('other fabricated etc.'), rubber products, chemicals and chemical products (including plastics) ('chemicals etc.'), structural metal products ('structural etc.'), electrical machinery ('electrical mach') and basic metal products ('basic metals'), respectively. Only the trade sector has high downstream effects. Efforts to enhance the effectiveness and competitiveness of the trade cluster should be directed towards enhancing the downstream effects. The trade cluster's supported output, employment (number), employment income and GDP are lower than actual figures, as shown in Table 9. This may be as a result of sectors in the cluster using up more domestic inputs. This will result in the cluster requiring fewer imports of intermediate goods as the cluster evolves to become more competitive and self-reliant.

\subsubsection{Dairy Products Cluster}

Although the dairy products cluster is small, it has high upstream (57\%) and downstream (54\%) linkages in the NWP economy (see Figure 10). The business services, chemicals and chemical products (including plastics) ('chemicals etc.') and community, social and personal services ('CSPS') sectors, respectively, have high upstream and low downstream effects. The trade sector has high downstream effects and moderate upstream effects. Most of the sectors in the dairy products cluster are located in the central lower part of Figure 10. This shows that the upstream effects of this cluster are relatively high. It also indicates that the downstream effects of this cluster are low and efforts should be directed towards enhancing these downstream effects in order to improve the cluster's effectiveness. With cluster formation, the dairy products sector will contribute more to the NWP economy. Table 10 in Appendix 2 shows that supported output, employment, employment income and GDP are greater than the actual figures.

The subsequent section illustrates the importance of the identified industrial clusters in terms of their economic impact on transformation of the structure of the NWP economy using an economic landscape matrix.

\subsection{The Economic Landscape of the NWP}

The economic landscape matrix Figure 11, discussed in this section is presented in Appendix 3. The first two matrices illustrated in Figure 11 (Appendix 3) show the pre- and post-cluster economic landscape of the NWP, while the third matrix shows the change (or difference) between pre- and post-economic structures. Note that the header numbers 1 through 37 represent the economic sectors of the NWP economy, as captured in the NWP SAM. Table 4 shows the descriptions associated with the numbers for the different economic sectors. The economic landscape also shows the hierarchy of forward and backward linkages of the economy (Khanal, 2011), ranking the 37 sectors in the NWP SAM according to the size of forward and backward linkages.

Figure 11 reveals 3 heat maps of the multiplier product matrix (MPM) for the pre-cluster, post-cluster and net change matrices associated with the promotion of cluster-specific exports. The rows represent the forward linkages (output produced by industries) while the columns represent the backward linkages (inputs required by industries). Forward linkages arise when there is an increase in final demand of a particular industry's products. That is, an increase in final demand of a particular industry's products results in additional production of inputs by other industries in order to meet the final demand. Backward linkages arise from the increase in demand for inputs from other industries. Industries with high backward linkages relative to other industries are important for an economy 
because it induces production in other industries. An industry with high forward linkages relative to other industries is sensitive to changes in other industries' output. In the first two matrices, the colour grading represents the relative size of the multiplier of each sector, ranging from dark grey for those sectors with relatively higher multiplier values and medium grey for those in between, tolight grey for the sectors with relatively lower multiplier values. In the third matrix, the dark grey shading represents increases in inter-industry linkages, while the light grey represents a reduction. The colour intensity in the charts represents the value of the inter-industry linkages. That is light grey represents a large reduction and light red represents relatively small losses, while dark green represents a large increase and light green represents moderate increases.

Table 4. Economic sectors in the NWP SAM

\begin{tabular}{ll|ll}
\hline \multicolumn{1}{c|}{ Sectors } & \multicolumn{2}{c}{ Sectors continued... } \\
\hline 1 & Agriculture & 20 & Other fabricated metal products \\
\hline 2 & Platinum mining & 21 & Machinery and equipment \\
\hline 3 & Gold mining & 22 & Electrical machinery and apparatus \\
\hline 4 & Other mining & 23 & Communication, medical and other electronic equipment \\
\hline 5 & Meat, fish, fruit, vegetables, oils and fat products & 24 & Manufacturing of transport equipment \\
\hline 6 & Dairy products & 25 & Other manufacturing and recycling \\
\hline 7 & Grain mill, bakery and animal feed products & 26 & Electricity \\
\hline 8 & Other food products & 27 & Water \\
\hline 9 & Beverages and tobacco products & 28 & Building and other construction \\
\hline 10 & Textiles, clothing, leather products and footwear & 29 & Trade \\
\hline 11 & Wood and wood products & 30 & Accommodation \\
\hline 12 & Furniture & 31 & Transport \\
\hline 13 & Paper and paper products & 32 & Communication \\
\hline 14 & Publishing and printing & 33 & Insurance \\
\hline 15 & Chemicals and chemical products (incl. plastic products) & 34 & Real estate \\
\hline 16 & Rubber products & 35 & Business services \\
\hline 17 & Non-metallic mineral products & 36 & General government services \\
\hline 18 & Basic metal products & 37 & Community, social and personal services \\
\hline 19 & Structural metal products & & \\
\hline Source & & \\
\hline
\end{tabular}

Source: Conningarth Economists, 2009

In the first matrix in Figure 11 - that is, the pre-industrial cluster formation - the top 5 key sectors in terms of backward linkages were: (1) dairy products, (2) grain mill, bakery and animal feed products, (3) meat, fish, fruit, vegetables, oils and fat products, (4) building and other construction, and (5) other food products. These economic sectors achieved higher hierarchies than the average of all sectors' hierarchies in the NWP. Sectors possessing average backward linkages were: accommodation; non-metallic mineral products; wood and wood products; electricity; and other mining. The following sectors were considered the least important sectors in the NWP based on the hierarchy of backward linkages before industrial cluster formation: business services; furniture; communication, medical and other electronic equipment; manufacturing of transport equipment; and general government services.

In terms of greater hierarchy of forward linkages, trade (ranked $1^{\text {st }}$ ), real estate (ranked $2^{\text {nd }}$ ), agriculture $\left(\right.$ ranked $\left.3^{\text {rd }}\right)$, community, social and personal services (ranked $4^{\text {th }}$ ) and basic metal products (ranked $5^{\text {th }}$ ) were the key sectors in the NWP prior to industrial cluster formation. Average performing sectors based on the greater hierarchy of forward linkages were: electrical machinery and apparatus; other food products; furniture; electricity; and beverages and tobacco products. Low performing sectors based on the hierarchy of forward linkages prior to industrial cluster formation were: wood and wood products; other manufacturing and recycling; publishing and printing; communication, medical and other electronic equipment; and general government services, as shown in Figure 11.

The second matrix in Figure 11 shows the structure of the economic landscape of the NWP economy postcluster formation. The results reveal that the top 5 key sectors in terms of backward linkages remained: (1) dairy products, (2) grain mill, bakery and animal feed products, (3) meat, fish, fruit, vegetables, oils and fat products, (4) building and other construction, and (5) other food products. The average performing sectors were: wood and wood products; accommodation; transport; non-metallic mineral products; and electricity. The sectors that were 
considered the least important in terms of backward linkages were: publishing and printing; business services; manufacturing of transport equipment; communication, medical and other electronic equipment; and general government services. In terms of forward linkages, the key performing sectors were: trade; real estate; agriculture; community, social and personal services; and other mining. The average performing sectors were: building and other construction; non-metallic mineral products; grain mill, bakery and animal feed products; electrical machinery and apparatus; and furniture. The sectors with the weakest forward linkages after industrial cluster formation in the NWP economy were: wood and wood products; other manufacturing and recycling; publishing and printing; communication, medical and other electronic equipment; and general government services.

From the three matrices in Figure 11, and especially the third matrix, one can clearly identify the sectors where changes occurred due to the promotion of cluster-specific exports. Significant shifts can be observed in the forward linkages or changes in output. Significant reductions are observed in other mining, and machinery and equipment output. In contrast, increases in output can be observed in the following sectors: other food products; chemicals and chemical products (including plastic products); meat, fish, fruit, vegetables, oils and fat products; dairy products; electricity; and trade. With regards to the backward linkages or the demand of inputs from other industries, significant increases occurred in the following sectors: communication, medical and other electronic equipment; and communication sectors. It is important to note that the identified industrial clusters are significant contributors to the structural change of the economic landscape of the NWP economy. That is, other food products, dairy products and trade achieved a significant gain in terms of forward linkages with the promotion of clusterspecific exports, while the backward linkages associated with the communication sector increased significantly with the promotion of cluster-specific exports.

Tables 5 and 6 show the changes in the economic structure of the NWP pre- and post-cluster formation. The tables show that the composition of the key sectors changes with industrial cluster formation. Similar differences are observed in the forward linkages for the key average and weak performing sectors. This indicates that industrial cluster formation will result in structural change in the NWP economy (see Tables 5 and 6 ). 
Table 5. Rankings of backward linkages in the NWP economy

\begin{tabular}{|c|c|c|c|}
\hline Sectors & Pre-cluster & & Post-cluster \\
\hline \multicolumn{4}{|l|}{ Key } \\
\hline 6 & Dairy products & 6 & Dairy products \\
\hline 7 & Grain mill, bakery and animal feed products & 7 & Grain mill, bakery and animal feed products \\
\hline 5 & $\begin{array}{l}\text { Meat, fish, fruit, vegetables, oils and fat } \\
\text { products }\end{array}$ & 5 & Meat, fish, fruit, vegetables, oils and fat products \\
\hline 28 & Building and other construction & 28 & Building and other construction \\
\hline 8 & Other food products & 8 & Other food products \\
\hline 34 & Real estate & 34 & Real estate \\
\hline 19 & Structural metal products & 19 & Structural metal products \\
\hline 32 & Communication & 9 & Beverages and tobacco products \\
\hline 9 & Beverages and tobacco products & 18 & Basic metal products \\
\hline 18 & Basic metal products & 29 & Trade \\
\hline 22 & Electrical machinery and apparatus & 20 & Other fabricated metal products \\
\hline 29 & Trade & 22 & Electrical machinery and apparatus \\
\hline \multicolumn{4}{|l|}{ Average } \\
\hline 20 & Other fabricated metal products & 11 & Wood and wood products \\
\hline 21 & Machinery and equipment & 30 & Accommodation \\
\hline 31 & Transport & 31 & Transport \\
\hline 30 & Accommodation & 17 & Non-metallic mineral products \\
\hline 17 & Non-metallic mineral products & 26 & Electricity \\
\hline 11 & Wood and wood products & 4 & Other mining \\
\hline 26 & Electricity & 21 & Machinery and equipment \\
\hline 4 & Other mining & 2 & Platinum mining \\
\hline 13 & Paper and paper products & 25 & Other manufacturing and recycling \\
\hline 1 & Agriculture & 13 & Paper and paper products \\
\hline 2 & Platinum mining & 32 & Communication \\
\hline 27 & Water & 27 & Water \\
\hline \multicolumn{4}{|l|}{ Weak } \\
\hline 25 & Other manufacturing and recycling & 3 & Gold mining \\
\hline 3 & Gold mining & 1 & Agriculture \\
\hline 15 & $\begin{array}{l}\text { Chemicals and chemical products (incl plastic } \\
\text { products) }\end{array}$ & 15 & $\begin{array}{l}\text { Chemicals and chemical products (incl plastic } \\
\text { products) }\end{array}$ \\
\hline 33 & Insurance & 33 & Insurance \\
\hline 10 & $\begin{array}{l}\text { Textiles, clothing, leather products and } \\
\text { footwear }\end{array}$ & 10 & Textiles, clothing, leather products and footwear \\
\hline 37 & Community, social and personal services & 37 & Community, social and personal services \\
\hline 16 & Rubber products & 16 & Rubber products \\
\hline 14 & Publishing and printing & 12 & Furniture \\
\hline 35 & Business services & 14 & Publishing and printing \\
\hline 12 & Furniture & 35 & Business services \\
\hline 23 & $\begin{array}{l}\text { Communication, medical and other electronic } \\
\text { equipment }\end{array}$ & 24 & Manufacturing of transport equipment \\
\hline 24 & Manufacturing of transport equipment & 23 & $\begin{array}{l}\text { Communication, medical and other electronic } \\
\text { equipment }\end{array}$ \\
\hline 36 & General government services & 36 & General government services \\
\hline
\end{tabular}


Table 6. Rankings of forward linkages in the NWP economy

\begin{tabular}{|c|c|c|c|}
\hline Sectors & Pre-cluster & & Post-cluster \\
\hline \multicolumn{4}{|l|}{ Key } \\
\hline 29 & Trade & 29 & Trade \\
\hline 2 & Platinum mining & 34 & Real estate \\
\hline 34 & Real estate & 1 & Agriculture \\
\hline 33 & Insurance & 37 & Community, social and personal services \\
\hline 4 & Other mining & 4 & Other mining \\
\hline 3 & Gold mining & 18 & Basic metal products \\
\hline 31 & Transport & 32 & Communication \\
\hline 37 & Community, social and personal services & 31 & Transport \\
\hline 32 & Communication & 33 & Insurance \\
\hline 28 & Building and other construction & 15 & $\begin{array}{l}\text { Chemicals and chemical products (incl plastic } \\
\text { products) }\end{array}$ \\
\hline 35 & Business services & 6 & Dairy products \\
\hline 17 & Non-metallic mineral products & 35 & Business services \\
\hline \multicolumn{4}{|l|}{ Average } \\
\hline 7 & Grain mill, bakery and animal feed products & 28 & Building and other construction \\
\hline 6 & Dairy products & 17 & Non-metallic mineral products \\
\hline 1 & Agriculture & 7 & Grain mill, bakery and animal feed products \\
\hline 26 & Electricity & 22 & Electrical machinery and apparatus \\
\hline 9 & Beverages and tobacco products & 12 & Furniture \\
\hline 18 & Basic metal products & 21 & Machinery and equipment \\
\hline 5 & $\begin{array}{l}\text { Meat, fish, fruit, vegetables, oils and fat } \\
\text { products }\end{array}$ & 3 & Gold mining \\
\hline 19 & Structural metal products & 9 & Beverages and tobacco products \\
\hline 25 & Other manufacturing and recycling & 2 & Platinum mining \\
\hline 8 & Other food products & 26 & Electricity \\
\hline 20 & Other fabricated metal products & 16 & Rubber products \\
\hline 22 & Electrical machinery and apparatus & 30 & Accommodation \\
\hline \multicolumn{4}{|l|}{ Weak } \\
\hline 30 & Accommodation & 8 & Other food products \\
\hline 15 & $\begin{array}{l}\text { Chemicals and chemical products (incl plastic } \\
\text { products) }\end{array}$ & 27 & Water \\
\hline 11 & Wood and wood products & 5 & Meat, fish, fruit, vegetables, oils and fat products \\
\hline 14 & Publishing and printing & 10 & Textiles, clothing, leather products and footwear \\
\hline 21 & Machinery and equipment & 19 & Structural metal products \\
\hline 16 & Rubber products & 13 & Paper and paper products \\
\hline 13 & Paper and paper products & 20 & Other fabricated metal products \\
\hline 27 & Water & 24 & Manufacturing of transport equipment \\
\hline 10 & $\begin{array}{l}\text { Textiles, clothing, leather products and } \\
\text { footwear }\end{array}$ & 11 & Wood and wood products \\
\hline 23 & $\begin{array}{l}\text { Communication, medical and other electronic } \\
\text { equipment }\end{array}$ & 25 & Other manufacturing and recycling \\
\hline 12 & Furniture & 14 & Publishing and printing \\
\hline 24 & Manufacturing of transport equipment & 23 & $\begin{array}{l}\text { Communication, medical and other electronic } \\
\text { equipment }\end{array}$ \\
\hline 36 & General government services & 36 & General government services \\
\hline
\end{tabular}

\section{CONCLUSION}

In the wake of the 2014 platinum sector strike it is crucial for the NWP to implement strategies to diversify its economy and to minimise the adverse effects of dependence on mineral resources. In this paper, the impact of industrial cluster formation as strategy to diversify the NWP economy was explored using SAM multiplier analysis. Solid evidence was provided to show that industrial cluster formation will enhance economic activity in the NWP based on the existing economic structure as captured in the SAM. This paper further illustrated the strength of the existing inter-industry linkages by quantifying and graphically presenting the backward and forward linkages 
between the clusters and their related sectors. In this way, the level of integration of the industries' inter-industry transactions was highlighted. The literature suggests that a cluster that is highly integrated, where the sectors in that cluster are highly dependent on each other's output, is shown by high upstream and downstream linkages. It is essential to understand how well the identified industrial clusters are interlinked with the different sectors in the NWP. With the identification of the clusters' inter-industry strengths to the different economic sectors, the economic sectors related to the clusters can be better informed of the opportunities that cluster formation presents. Of the ten identified clusters for the NWP, the following were found to be moderately integrated: (i) trade (ii) basic metal products (iii) grain mill, bakery and animal feed products, and (iv) building and other construction. These clusters have high upstream effects. Efforts to promote industrial cluster formation should aim to enhance the inter-industry linkages, particularly the downstream effects in these clusters, as they already have moderately high existing upstream effects. This would make the clusters more integrated and would enhance the effects (power-of-pull) of the clusters. For the rest of the clusters, namely communication, real estate, other food products, agriculture and nonmetallic mineral products, the levels of cluster integration were found to be weak. Therefore, efforts to promote industrial cluster formation should aim to enhance both the upstream and downstream effects.

SAM-based multiplier analysis was used to demonstrate the output, employment, employment income and GDP supported by cluster formation for the NWP. This was demonstrated by comparing the actual activity (output, employment, employment income and GDP, given in the SAM) with the supported activity (computed using SAM data and the multipliers) for each cluster. The literature suggests that the supported activity of clusters is expected to be higher than the direct activity owing to the enhanced competitiveness of clusters. Contrary to the literature, though, the supported activity for the agriculture and trade clusters was less than the actual activity. As supported by the literature, the following clusters' supported activity was greater than the actual activity: communication; real estate; grain mill, bakery and animal feed products; building and other construction; basic metal products; other food products; non-metallic mineral products; and dairy products.

Finally, this paper demonstrated, using economic landscaping, that industrial cluster formation will result in a structural change to the NWP economy. This was shown by the changes in the hierarchies of backward and forward linkages of the different sectors in the province. It is important to note that the identified industrial clusters are significant contributors to the structural change of the economic landscape of the NWP economy. That is, other food products, dairy products and trade gained significantly in terms of forward linkages with the promotion of cluster-specific exports, while the backward linkages associated with the communication sector increased significantly with the promotion of cluster-specific exports. In conclusion, this paper provided evidence that industrial cluster formation enhances competitiveness and economic diversification.

The authors recommend that the NWP government promote industrial cluster formation as a strategy to enhance competitiveness and economic diversification. The provincial government should assume a catalytic role and initiate the industrial cluster formation process by bringing vested interests together to encourage collaboration. This will help to reveal the extent of cooperation between firms in the clusters and stimulate interest in the potential benefits of cluster formation, and is an important step because the quantitative analysis conducted in the study offers no insight into the cluster characteristics, such as active networks, learning and innovation, or the sharing of information or equipment. Once the cluster formation process is initiated, the provincial government should formulate a cluster development strategy outlining the various stakeholders involved and the objectives of the exercise, and decide on the optimal means by which the objectives should be achieved. Furthermore, the cluster development strategy should outline the steps involved in implementation, monitoring and evaluation.

The provincial government could take the catalytic role a step further by providing infrastructure, education or training. Alternatively, the government's role could be directive, which would entail implementing policies to improve the local business environment, such as reviewing tax rules, reducing costs of services, and providing market or competitor information. These are important considerations as the ten clusters identified in this study include several related sectors which together account for a large proportion of the economic sectors in question. 


\section{AUTHOR INFORMATION}

Noleen Pisa is a post doctoral researcher in the TRADE research niche at the North West University (Potchefstroom Campus). She holds a PhD in International Trade as well as a M.Com in International Trade (with distinction) from the same institution. Her research interests include competitiveness, industrial cluster formation, economic and socio-economic impact assessments, market analysis, market accessibility, policy analysis and economic modelling and export promotion. She has worked as a consultant for the International Trade Centre in Geneva, Switzerland. Email: 21246165@nwu.ac.za (corresponding author)

Riaan Rossouw is a micro-economist with more than 11 years' applied research and teaching experience. He is currently an associate professor in the School of Economics at the North-West University. His research interests include social and economic dimensions of inequality, economic impact assessment, decision support systems as well as applied/computable general equilibrium modelling, particularly as applied in the African (and South African) contexts, with a special focus on regional disparities, labour markets, fiscal reform, tourism, energy policy, development planning and international trade. Riaan has carried out consultancy work for numerous entities, including governmental departments, financial institutions, private companies, international organisations, international business schools, and real economy institutions such as mining houses, freight transport companies and utility providers. E-mail: riaan.rossouw@nwu.ac.za

Wilma Viviers is since July 2014 the holder of the prestigious WTO Chair, leader of the TRADE research entity and NRF-rated researcher at the North-West University (Potchefstroom Campus). Prof Viviers' research interest in the realisation of and strategies to improve South Africa's trade performance and competitiveness are acknowledged both locally and internationally. Notably, the Decision Support Model (DSM) for the identification of South African export opportunities - which she has launched in this country - is being lauded in both government and business circles as a refreshingly efficient approach to export market selection. Prof Viviers sits on several national and international committees and has received numerous awards in recognition of her ground-breaking research over the years. E-mail: wilma.viviers@nwu.ac.za

\section{REFERENCES}

Alers. L. (2014). Counting costs of mining strikes worst yet to come. Biznews.com. Retrieved from: http://www.biznews.com/thought-leaders/2014/07/counting-costs-sa-mining-strikes-worst-yet-come-analyst._Date of access: 13 January 2015.

Adelman, I. \& Robinson, S. (1989). Income distribution and development. In J. Chenery, \& P. Srinivasan (Eds.), Handbook of development economics, Vol II, Amsterdam:North Holland.

Bess, R. \& Ambargis Z. O. (2011). Input-output models for impact analysis: Suggestions for practitioners using RIMS II multipliers. 50th Southern Regional Science Association Conference, March 23-27, 2011, New Orleans, Louisiana, USA.

Bonet, J. (2005). Regional structural changes in Colombia: An input-output approach. Borradores de Economia. $\mathrm{PhD}$ thesis. North Holland. Retrieved February 14, 2014, from http://www.banrep.gov.co/docum/ftp/borra341.pdf. .

Breisinger, C., Thomas, M. \& Thurlow, J. (2010). Social accounting matrices and multiplier analysis: an introduction with exercises. Food Security in Practice technical guide 5. Washington, DC: International Food Policy Research Institute.

Ciaschini, M. \& Socci, C. (2007). Final demand impact on output: a macro multiplier approach. Journal of Policy Modelling 29, 115-132.

Conningarth Economists. (2009). Provincial social accounting matrix for the North-West Province. Report prepared for the North-West Province Government.

Czamanski, S. (1974). Study of clustering of industries. Institute of Public Affairs. Halifax, Canada: Dalhousie University.

Defourny, J. \& Thorbecke, E. (1984). Structural path analysis and multiplier decomposition within a social accounting matrix framework. The Economic Journal, 94, 111 - 136.

Dietzenbacher, E. (1992). The measurement of inter-industry linkages: key sectors in the Netherlands. Economic Modelling, 9, 419-437. 
Eitzen, H. C. (2012). Dilemmas of diversification: Regional economic development and business-industrial clusters in China and Kazakhstan. Journal of Emerging Knowledge on Emerging Markets, 4(1/2), 2-26.

Guo, J. \& Planting, M.A. (2000). Using Input-Output analysis to measure U.S. economic structural change over a 24 year period. Paper presented at The 13th International Conference on Input-Output Techniques, Macerata, Italy August 21-28, 2000.

Hayden, C. \& Round, J. I. (1982). Developments in social accounting methods as applied to the analysis of income distribution and employment issues. World Development, 10:451-65.

Hewings, G. J. D. (1974). The effect of aggregation on the empirical identification of key sectors in a regional economy: a partial evaluation of alternative techniques. Environment and Planning A, 6, 439-453.

Hirschman, A. O. (1958). The strategy of economic development. New Haven, CT: Yale University Press.

Honkatukia, J. 2013. The VATTAGE regional model VERM - a dynamic, regional, applied general equilibrium model of the Finnish economy. Government Institute for Economic Research. VATT Research Reports $171 / 2013$.

Khanal, B. R. (2011). An economic analysis of the Lao PDR tourism industry. PhD thesis. Lincoln University.

Kingstone, P. (2012). Brazil's reliance on commodity exports threatens its medium- and long-term growth prospects. Retrieved May 15, 2014, from http://www.americasquarterly.org/kingstone.

Learmonth, D., Munro, A. \& Swales, K.J. (2003). Multi-sectoral cluster modelling: the evaluation of Scottish enterprise cluster policy. European Planning Studies, 11(5):567-584.

Lee, K. C. (1986). Input output multipliers with backward forward and total linkages. Paper presented at the $8^{\text {th }}$ international conference on input-output techniques.

Lima, M., Cardenete, A. \& Vallés Ferrer, J. (2003). Structural path analysis: Applications to structural changes in the Andalusian economy 1990-1999. European Regional Science Association ERSA 2003 Congress.

Martin, R. \& Sunley, P. (2003). Deconstructing clusters: chaotic concept or policy panacea? Journal of Economic Geography, 3:5-35.

Miller, R. E. \& Blair, P. D. (1985). Input-output analysis: foundations and extensions. Englewood Cliffs, NJ: Prentice-Hall.

Newman, M.E.J. (2008). Mathematics of networks. In, L. E. Blume and Durlauf, S. N. (Eds). The new Palgrave encyclopaedia of economics. $2^{\text {nd }}$ ed. Basingstoke: Palgrave Macmillan). http://wwwpersonal.umich.edu/ mejn/papers/palgrave.pdf. Date of access: 01/06/2011.

Parra, J. C. \& Wodon, Q. (2009). SimSIP_SAM: A tool for the analysis of Input - Output tables and Social Accounting Matrices. Washington DC: World Bank.

Parré, J. L., Alves, A. F., \& Sordi, J. C. (2002). Input-output matrix for metropolitan areas using local census data: The case of Maringà, Brazil. Council for the Economical Development of Maringá.

Pisa, N. 2014. Identifying industrial clusters for competitiveness: Policy implications for economic development in the North West Province of South Africa. Unpublished PhD Thesis, North West University (Potchefstroom Campus), South Africa.

Platinum Wage Negotiations. (2015). Financial impact of strike. Retrieved from:

http://www.platinumwagenegotiations.co.za. Date of access: 14 January 2015.

Polenske, K. R. \& Jordan, P. (1988). A multiplier impact study of fishing. In M. Ciaschini (Ed), Input output analysis current developments. London: Chapman and Hall.

Porter, M. E. (2002). Clusters of innovation initiative: Pittsburgh. Washington, DC: Council on competitiveness. Retrieved October 28, 2013, from http://www.compete.org/images/uploads/File/PDF\%20Files/CoC Pitts cluster final.pdf.

Pyatt, G. \& Round, J. (1979). Accounting and fixed price multipliers in a social accounting matrix framework. The Economic Journal, 89, 850-873.

Pyatt, G. \& Thorbecke, E. (1976). Planning techniques for a better future. Geneva: ILO.

Quantec Easydata. (2013). Regional indicators. Retrieved February 1, 2013, from www.easydata.co.za.

Rasmussen, P. N. (1956). Studies in intersectoral relations. Amsterdam: North Holland.

Robinson, S. (1989). Multi-sectoral model. In J. Chenery \& P. Srinivasan (Eds.), Handbook of development economics, Vol II. Amsterdam: North Holland.

Round, J. (2003). Social accounting matrices and SAM-based multiplier analysis. In L. A. Da Silva Pereira \& F. Bourguignon (Eds), Techniques for evaluating the poverty impact of economic policies. Washington D.C: 
World Bank.

Singh, S. (2014). Effects of the mining strikes on the South African economy. Retrieved from: http://www.miningreview.com/effects-of-the-mining-strikes-on-the-south-african-economy. Date of access: 13 January 2015.

Solomons, I. (2014). Platinum strike consequences starting to take shape. Retrieved from:

http://www.miningweekly.com/article/platinum-strike-consequences-starting-to-take-shape-2014-08-22. Date of access: 13 January 2015.

Sonis, M., Hewings, G. J. D. \& Guo, J. (2000). A new image of classical key sector analysis: Minimum information decomposition of the Leontief inverse. Economic Systems Research, 12(3), 401-423.

South African Reserve Bank (SARB). (2014). Quarterly bulletin, June 2014. . Retrieved from: https://www.resbank.co.za/Lists/News\%20and\%20Publications/Attachments/6273/01Full\%20Quarterly\%2 0Bulletin\%20\%E2\%80\%93\%20June\%202014.pdf. Date of access: 13 January 2015. 
APPENDIX 1: FIGURES FOR NWP OUTPUT, EMPLOYMENT, INCOME AND GDP SUPPORTED BY INDUSTRIAL CLUSTER FORMATION

Figure 4. Upstream and downstream linkage effects of the NWP building and other construction cluster and related sectors

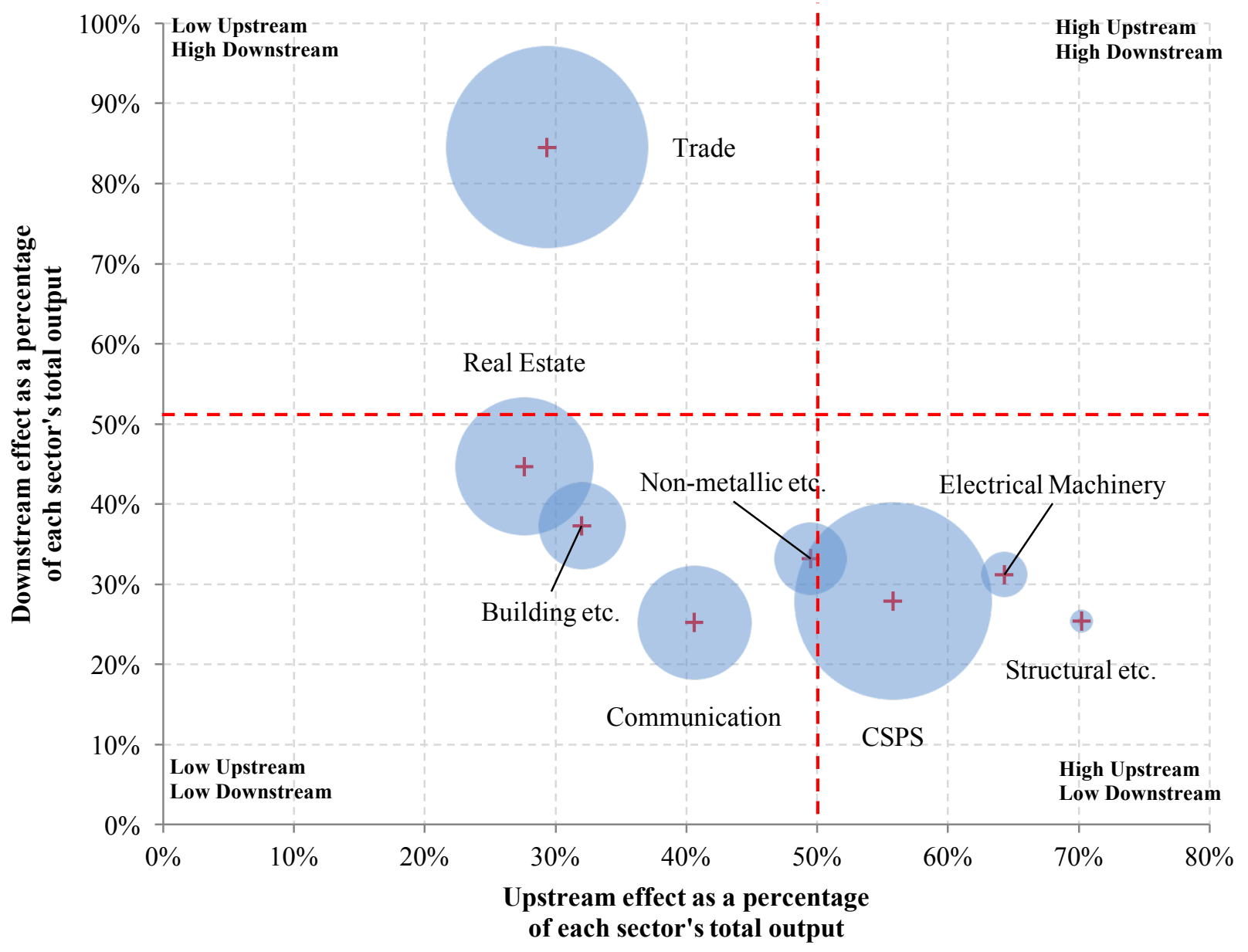

Source: Compiled by authors from Conningarth Economists SAM, 2009 
Figure 5. Upstream and downstream linkage effects of the NWP basic metal products cluster and related sectors

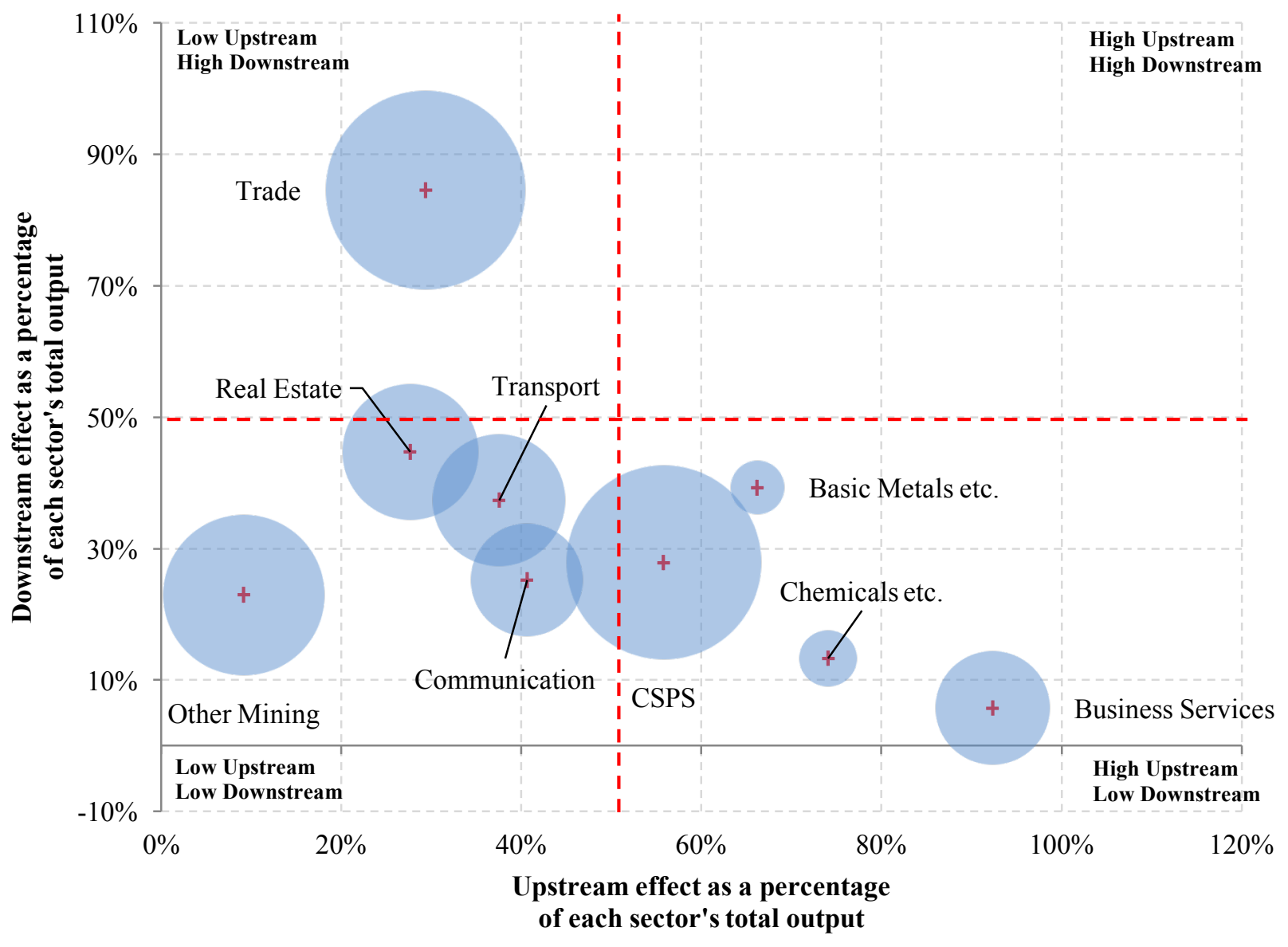

Source: Compiled by authors from Conningarth Economists SAM, 2009 
Figure 6. Upstream and downstream linkage effects of the NWP other food products cluster and related sectors

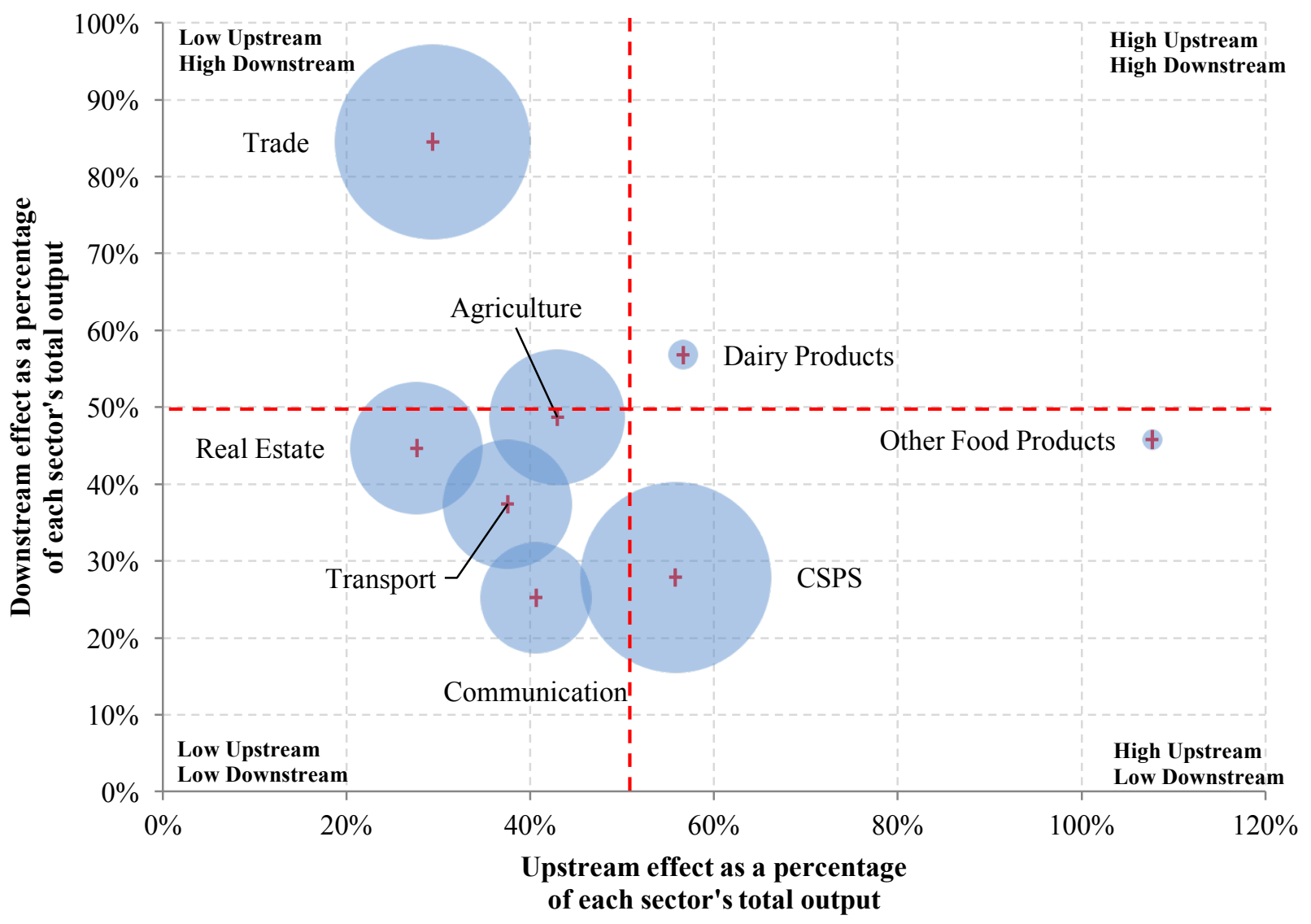

Source: Compiled by authors from Conningarth Economists SAM, 2009 
Figure 7. Upstream and downstream linkage effects of the NWP agriculture cluster and related sectors

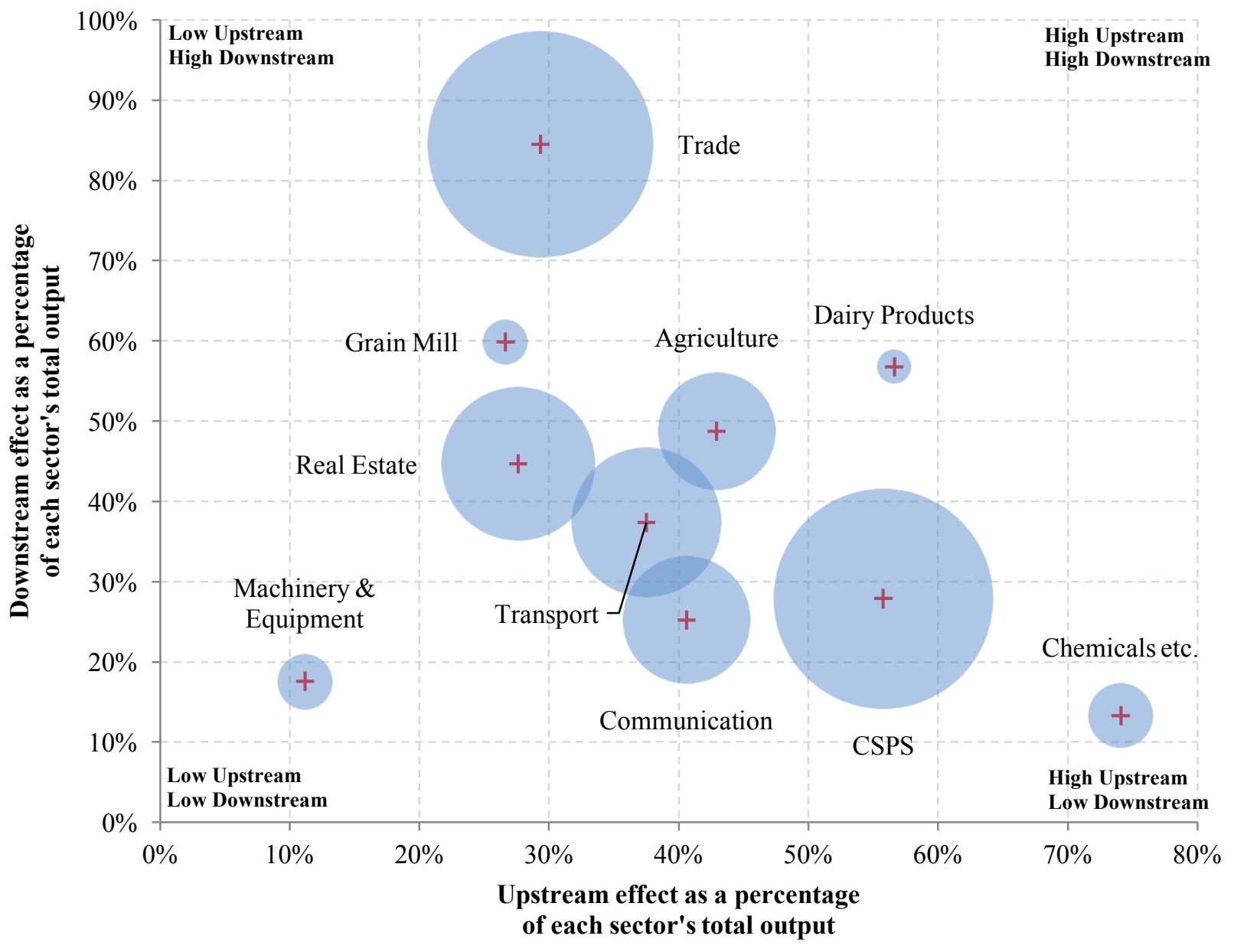

Source: Compiled by authors from Conningarth Economists SAM, 2009 
Figure 8. Upstream and downstream linkage effects of the NWP non-metallic mineral products cluster and related sectors

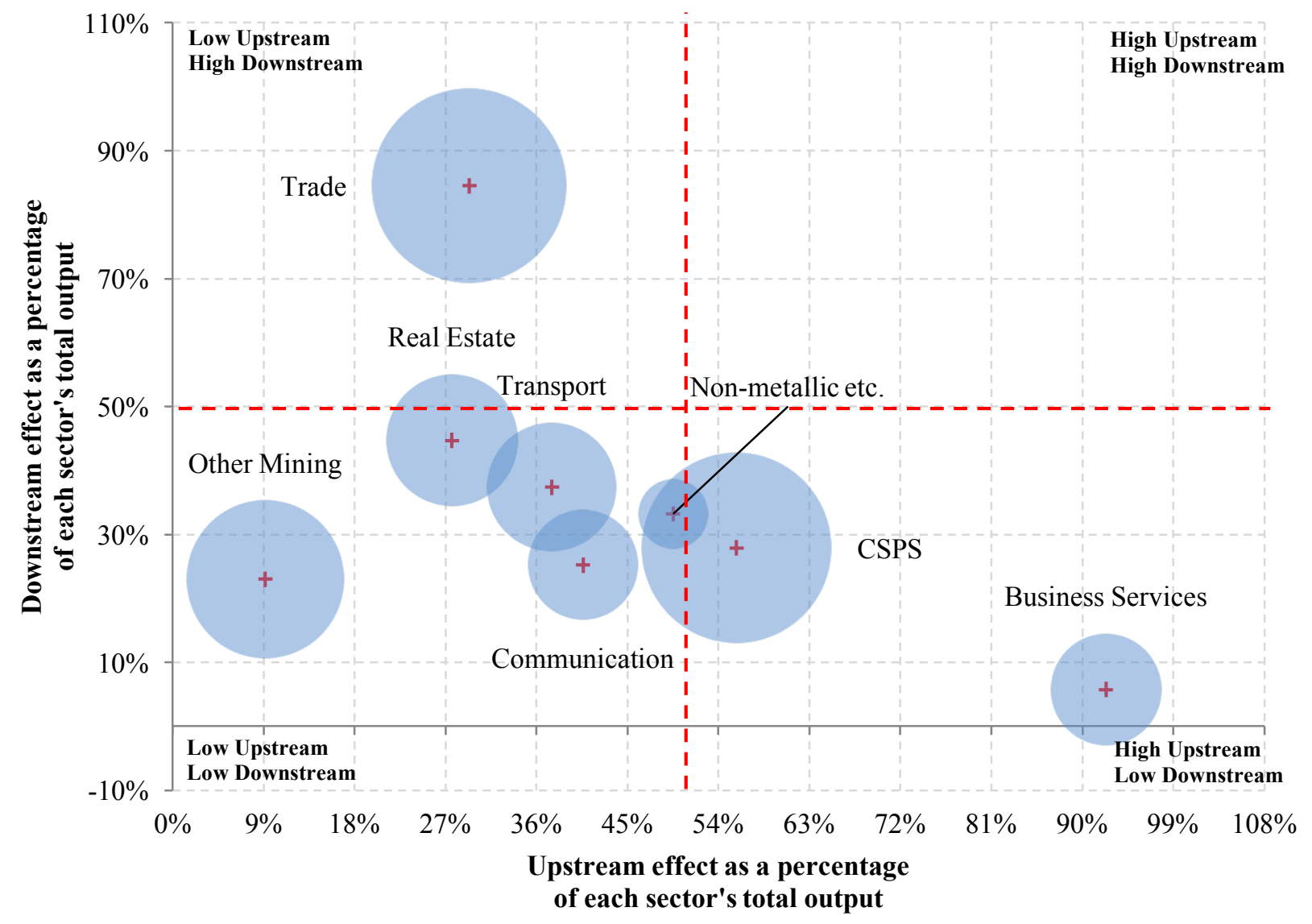

Source: Compiled by authors from Conningarth Economists SAM, 2009 
Figure 9. Upstream and downstream linkage effects of the NWP trade cluster and related sectors

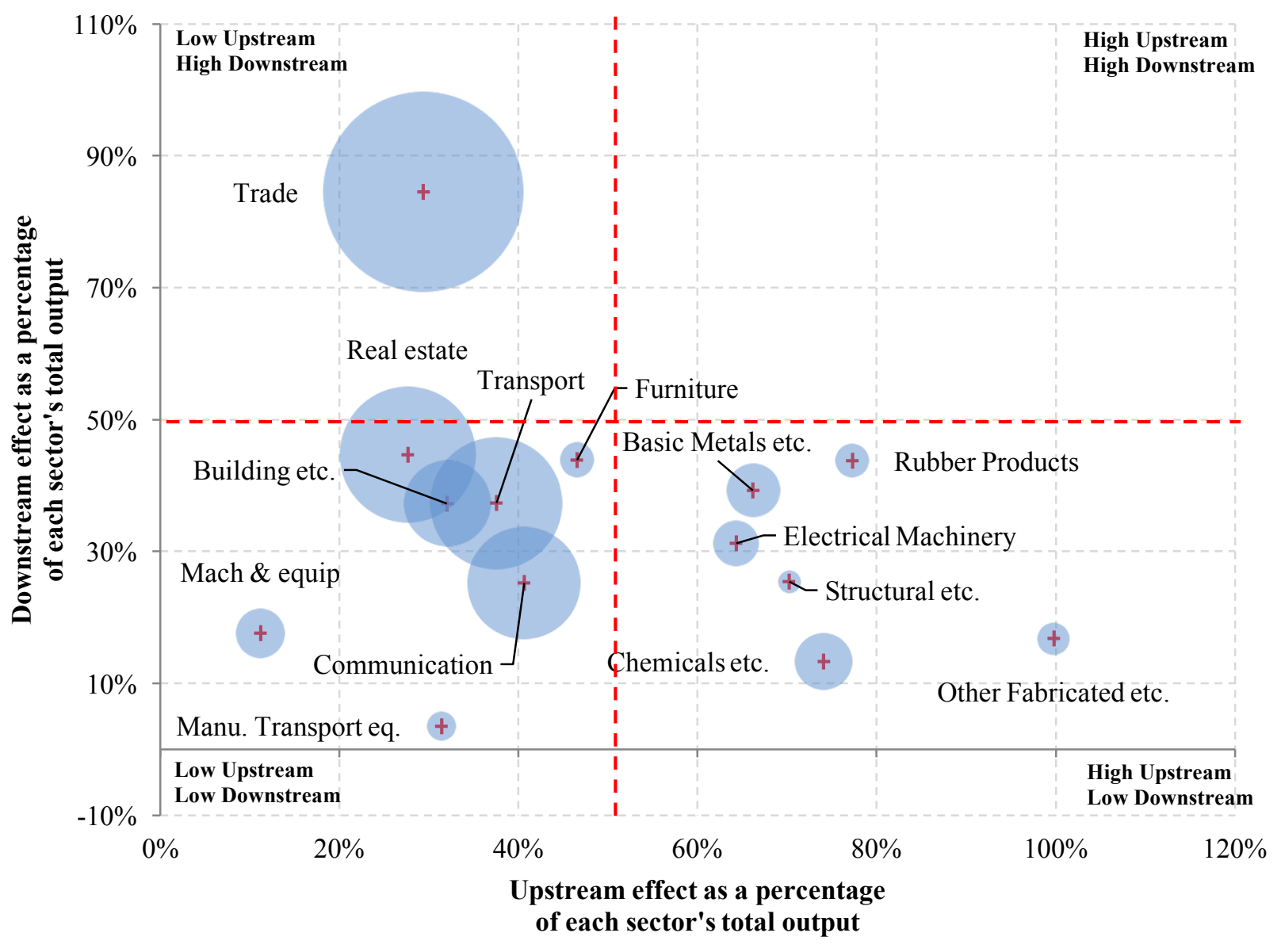

Source: Compiled by authors from Conningarth Economists SAM, 2009 
Figure 10. Upstream and downstream linkage effects of the NWP dairy products cluster and related sectors

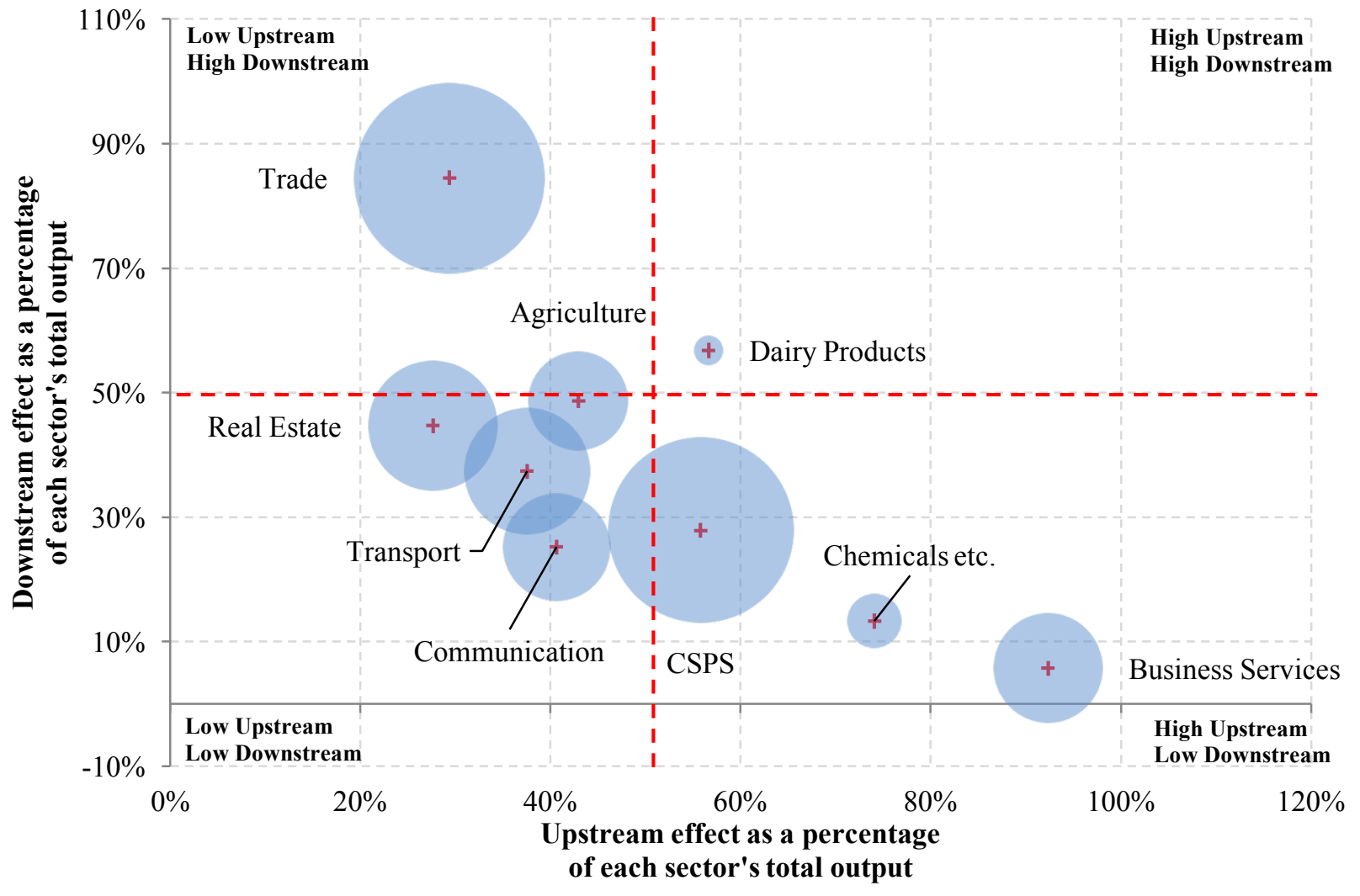

Source: Compiled by authors from Conningarth Economists SAM, 2009 


\section{APPENDIX 2: TABLES FOR NWP OUTPUT, EMPLOYMENT, INCOME AND GDP SUPPORTED BY INDUSTRIAL CLUSTER FORMATION}

Table 7. NWP output, employment, income and GDP supported by the building and other construction industry cluster

\begin{tabular}{lcccc}
\hline & $\begin{array}{c}\text { Output } \\
\text { (ZAR millions) }\end{array}$ & $\begin{array}{c}\text { Employment } \\
\text { (Number) }\end{array}$ & $\begin{array}{c}\text { Employment income } \\
\text { (ZAR millions) }\end{array}$ & $\begin{array}{c}\text { GDP } \\
\text { (ZAR millions) }\end{array}$ \\
\hline Actual & 9.271 & 35333 & 1.133 & 2.206 \\
Supported & 14.260 & 56577 & 4.248 & 5.495 \\
\hline
\end{tabular}

Source: Conningarth Economists, 2009 and Quantec Easy Data, 2014

Table 8. NWP output, employment, income and GDP supported by the basic metal products industry cluster

\begin{tabular}{lcccc}
\hline & $\begin{array}{c}\text { Output } \\
\text { (ZAR millions) }\end{array}$ & $\begin{array}{c}\text { Employment } \\
\text { (Number) }\end{array}$ & $\begin{array}{c}\text { Employment income } \\
\text { (ZAR millions) }\end{array}$ & $\begin{array}{c}\text { GDP } \\
\text { (ZAR millions) }\end{array}$ \\
\hline Actual & 4.174 & 7198 & 343 & 894 \\
Supported & 7.108 & 20602 & 1.836 & 2.993 \\
\hline
\end{tabular}

Source: Conningarth Economists, 2009 and Quantec Easy Data, 2014

Table 9. NWP output, employment, income and GDP supported by the other food products industry cluster

\begin{tabular}{lcccc}
\hline & $\begin{array}{c}\text { Output } \\
\text { (ZAR millions) }\end{array}$ & $\begin{array}{c}\text { Employment } \\
\text { (Number) }\end{array}$ & $\begin{array}{c}\text { Employment income } \\
\text { (ZAR millions) }\end{array}$ & $\begin{array}{c}\text { GDP } \\
\text { (ZAR millions) }\end{array}$ \\
\hline Actual & 352 & 2931 & 49 & 106 \\
Supported & 519 & 3292 & 162 & 215 \\
\hline
\end{tabular}

Source: Conningarth Economists, 2009 and Quantec Easy Data, 2014

Table 10. NWP output, employment, income and GDP supported by the agriculture industry cluster

\begin{tabular}{lcccc}
\hline & $\begin{array}{c}\text { Output } \\
\text { (ZAR millions) }\end{array}$ & $\begin{array}{c}\text { Employment } \\
\text { (Number) }\end{array}$ & $\begin{array}{c}\text { Employment income } \\
\text { (ZAR millions) }\end{array}$ & $\begin{array}{c}\text { GDP } \\
\text { (ZAR millions) }\end{array}$ \\
\hline Actual & 8.286 & 81.088 & 882 & 4.188 \\
Supported & 6.050 & 27.633 & 2.913 & 2.529 \\
\hline
\end{tabular}

Source: Conningarth Economists, 2009 and Quantec Easy Data, 2014

Table 11. NWP output, employment, income and GDP supported by the non-metallic mineral products industry cluster

\begin{tabular}{lcccc}
\hline & $\begin{array}{c}\text { Output } \\
\text { (ZAR millions) }\end{array}$ & $\begin{array}{c}\text { Employment } \\
\text { (Number) }\end{array}$ & $\begin{array}{c}\text { Employment income } \\
\text { (ZAR millions) }\end{array}$ & $\begin{array}{c}\text { GDP } \\
\text { (ZAR millions) }\end{array}$ \\
\hline Actual & 3.2745 & 16328 & 639 & 1.046 \\
Supported & 4.822 & 15971 & 1.442 & 2.075 \\
\hline
\end{tabular}

Source: Conningarth Economists, 2009 and Quantec Easy Data, 2014

Table 12. NWP output, employment, income and GDP supported by the trade industry cluster

\begin{tabular}{lcccc}
\hline & $\begin{array}{c}\text { Output } \\
\text { (ZAR millions) }\end{array}$ & $\begin{array}{c}\text { Employment } \\
\text { (Number) }\end{array}$ & $\begin{array}{c}\text { Employment income } \\
\text { (ZAR millions) }\end{array}$ & $\begin{array}{c}\text { GDP } \\
\text { (ZAR millions) }\end{array}$ \\
\hline Actual & 21.685 & 89816 & 5.332 & 10.786 \\
Supported & 10.532 & 30595 & 5.212 & 4.868 \\
\hline Source: Conningarth Economists, 2009 and Quantec Easy Data, 2014 & &
\end{tabular}

Source: Conningarth Economists, 2009 and Quantec Easy Data, 2014

Table 13. NWP output, employment, income and GDP supported by the dairy products industry cluster

\begin{tabular}{lcccc}
\hline & $\begin{array}{c}\text { Output } \\
\text { (ZAR millions) }\end{array}$ & $\begin{array}{c}\text { Employment } \\
\text { (Number) }\end{array}$ & $\begin{array}{c}\text { Employment income } \\
\text { (ZAR millions) }\end{array}$ & $\begin{array}{c}\text { GDP } \\
\text { (ZAR millions) }\end{array}$ \\
\hline Actual & 1.868 & 2430 & 108 & 427 \\
Supported & 4.486 & 16790 & 700 & 982 \\
\hline
\end{tabular}

Source: Conningarth Economists, 2009 and Quantec Easy Data, 2014 


\section{APPENDIX 3: ECONOMIC LANDSCAPES OFTHE NWP PRE- AND POST-INDUSTRIAL CLUSTER FORMATION}

Pre-cluster economic landscape for the NWP

Figure 11. Total multiplier landscapes for the NWP

\begin{tabular}{|c|c|c|c|c|c|c|c|c|c|c|c|c|c|c|c|c|c|c|c|c|c|c|c|c|c|c|c|c|c|c|c|c|c|c|c|c|}
\hline & 2 & & & & & & & & & & & & & & & & & & & & & & & & & & & & & & & & & & & \\
\hline & 925 & & 941 & & 637 & 3523 & 3265 & 3113 & 0.2819 & 0.2996 & 0.2673 & 0.2005 & 2654 & 0.2848 & 0.2757 & 982 & 3093 & 3181 & 0.3058 & 0.2936 & 0.3046 & 136 & 0.2495 & 0.2909 & 0.2958 & 0.2886 & 0.3360 & 3078 & 0.2994 & 0.2990 & 0.2899 & 0.2822 & 0.3253 & 0.2627 & 6860 & \\
\hline 0.0735 & 150 & & 754 & & 1933 & 903 & & 798 & 0723 & 768 & 685 & 745 & 680 & & 707 & 765 & 793 & 1816 & 784 & 753 & 781 & 1548 & 0.0640 & 0746 & 0.0759 & 1740 & 1862 & 789 & & 767 & 0.0743 & 0.0723 & 834 & & & 071 \\
\hline 0.0744 & 1758 & 745 & 763 & 0910 & 9943 & 0.0913 & 1847 & 0807 & 0731 & & 0693 & 7753 & 0688 & 0738 & 0.0715 & 0.0773 & & 0825 & .0793 & 0.0761 & 0.0790 & 0.0554 & 0.0647 & 0.0754 & 0.0767 & 0.0748 & 0.0871 & 0798 & & 0.0775 & 0.0751 & 0.0731 & .0843 & 6881 & 017 & 0.071 \\
\hline 0.1922 & 1960 & 1926 & 1971 & 0.2354 & 2438 & 0.3361 & 0.2189 & 2086 & 0.1890 & 0.2008 & 1792 & 1.947 & 0.1779 & 0.1909 & 0.1848 & 0.1999 & 2073 & 0.2132 & 0.2049 & 0.1968 & 0.2042 & 0.1432 & 0.1672 & 0.1950 & 0.1983 & 0.1934 & 0.2252 & 0.2063 & 12006 & 0.2004 & 0.1943 & 0.1891 & 0.2180 & 0.1761 & 1.0460 & 0.185 \\
\hline 0.0673 & 0686 & 0674 & 0.0690 & 0.0824 & 9853 & .0826 & 0766 & .0730 & 0.0661 & .0703 & .0627 & 0681 & 1.0622 & 0.0668 & 0.0647 & 0.0699 & 0.0725 & .0746 & 0.0717 & 0.0688 & 0.0714 & 0.0501 & 0.0585 & 0682 & 0.0694 & 0.0677 & 0.0788 & 0.0722 & 0702 & 0.0701 & 0.0680 & 0.0662 & .0763 & .061 & .016 & 0.065 \\
\hline 0.1410 & 1437 & 1412 & 0.1446 & 0.1726 & 1788 & 0.1731 & 1.1605 & 1.1530 & 0.1386 & 0.1472 & 1314 & 0.1428 & 0.1304 & 0.1400 & 0.1355 & 0.1466 & 0.1520 & 0.1564 & 0.1503 & 0.1443 & 0.1497 & 0.1050 & 0.1226 & 0.1430 & 0.1454 & 0.1418 & 0.1651 & 0.1513 & .1471 & 0.1470 & 0.1425 & 0.1387 & 0.1599 & .12 & .03 & 0.136 \\
\hline 1061 & 1081 & .1063 & 1.088 & 0.1299 & 1345 & . 1303 & .1207 & 11151 & 0.1042 & 0.1108 & 1.0989 & 0.1074 & .0981 & 0.1053 & 0.1019 & 0.1103 & 1144 & 1176 & 0.131 & 0.1085 & 0.1126 & 0.0790 & 0.0922 & 1076 & 0.1094 & 0.1067 & 0.1242 & 0.1138 & 107 & .1106 & 0.1072 & 0.1043 & 0.1203 & 0.097 & 0.02 & 0.102 \\
\hline 707 & 0721 & 0708 & 0.725 & 0.0866 & 8997 & .0869 & 0805 & 0767 & 0.0695 & 0.0739 & 1.059 & .0716 & .0654 & 0.0702 & 0.0680 & 0.0735 & 1763 & 0784 & 0.0754 & 0.0724 & 0.0 & 0.0527 & 0.0615 & 0717 & 0.0729 & 0.0711 & 0.0828 & 0.0759 & 0.0738 & 10737 & 0.0715 & 0.0696 & 0.0802 & 06 & 0.0 & 0.068 \\
\hline 742 & & & 760 & & & & & & & & & & & & & & & & 791 & 59 & 788 & & 645 & & 165 & 7746 & & & & & & 0.0729 & & & & .071 \\
\hline 0.0671 & 0684 & 672 & 688 & 0821 & 850 & 1824 & & 728 & 0.0659 & & 625 & 679 & 0620 & 0.066 & 0.0645 & 0.0697 & & 0744 & 0.0715 & 0.0686 & 0.0712 & 0.0499 & 0.0583 & .0.800 & 0.0692 & 0.0675 & 0.0786 & 0.0720 & 0.0700 & 0.0699 & 0.0678 & 0.0660 & $0 / 101$ & & .01 & 0.064 \\
\hline 0.0469 & 0479 & 040 & 0481 & 0.0575 & 1595 & 0576 & 0534 & 0509 & 0.0461 & 0.0490 & 0.0437 & 0475 & .0434 & 0.0466 & 0.0451 & 0.0488 & 0.0506 & .0521 & 0.0500 & 0.0480 & 0.048 & 0.0350 & 0.0408 & 0.0476 & 0.0484 & 0.0472 & 0.0550 & 0.0504 & 0.040 & 0.0489 & 0.0474 & 0.0462 & 0.0532 & .043 & .01 & 0.045 \\
\hline 0.0823 & 0839 & .0824 & 0.0844 & 0.1007 & 1043 & 1011 & 0.0937 & 0.0893 & 0.0809 & 0.0859 & 0.0767 & 0.0833 & 0.0761 & 0.0817 & 0.0791 & 0.0855 & 0.0887 & 0.0913 & 0.0877 & 0.0842 & 0.0874 & 0.0613 & 0.0716 & 0.0834 & 0.0849 & 0.0828 & 0.0964 & 0.0883 & 0.0859 & 0.0858 & 0.0831 & 0.0809 & 0.0933 & 0.075 & 0.019 & 0.079 \\
\hline 0.0598 & 0610 & 0599 & .0613 & 0.0732 & 0758 & 1.0734 & 0.0681 & 0.0649 & 0.0588 & 0.0625 & 0.0557 & 0.0606 & 0.0553 & 0.0594 & 0.0575 & 0.0622 & 0.0645 & 0.0663 & 0.0637 & 0.0612 & 0.0635 & 0.0445 & 0.5520 & 0.0606 & 0.0617 & 0.0602 & 0.0700 & 0.0642 & 0.0624 & 0.0623 & 0.0604 & 0.0588 & 0.0678 & 0.054 & .01 & 0.057 \\
\hline 0.0425 & 0433 & 0425 & .0435 & 0.0520 & 0538 & 0521 & 0483 & 0.041 & 0.047 & 0.0443 & 1.0396 & .0430 & 0.0393 & 0.0422 & 0.0488 & 0.0441 & 0.0458 & 0.0471 & 0.0453 & 0.0435 & 0.0451 & 0.0316 & 0.0369 & 0.0431 & 0.0438 & 0.0427 & 0.0497 & 0.0456 & 0.0443 & 0.0433 & 0.0429 & 0.0418 & 0.0481 & 0.0389 & 0.011 & 0.041 \\
\hline 0.1411 & 1438 & 413 & 1447 & 0.1727 & 1789 & 1733 & & 531 & 0.1387 & 01473 & 1315 & 1428 & 1305 & 1.401 & 0.1356 & 0.1466 & & 1.1565 & 1504 & 0.1444 & & 105 & & & 0.145 & 0.141 & & 514 & & & 0.142 & 0.13 & & 0.12 & 0 & .136 \\
\hline 0.0731 & 774 & 732 & 749 & 0895 & 0927 & 0897 & & 793 & 0718 & 0763 & 6881 & 0740 & 0676 & 0726 & 0.0702 & 0.0760 & 788 & 0810 & .0779 & 0.0748 & 0.0776 & 0.0544 & .0636 & 7741 & 0.0754 & 0.0735 & & 0784 & & & 0.0738 & & & & & .070 \\
\hline 0.1104 & 125 & & 132 & 0.1352 & 400 & 136 & & & 085 & & 029 & 118 & 1021 & .1096 & 0.1061 & 147 & & 1224 & .1177 & 0.1130 & 172 & 8822 & 0.0460 & & 0.1138 & 0.1110 & & .1184 & & & 0.1115 & 0.10 & & 1011 & 02 & 1.106 \\
\hline 0.1754 & 1789 & 1758 & 1799 & 0.2148 & 2225 & 2155 & 1997 & 1904 & 0.1724 & 0.1832 & 1635 & 1777 & 1.1623 & 0.1742 & 0.1686 & 0.1824 & 1892 & 0.1946 & 0.1870 & 0.1796 & 0.1863 & 0.1307 & 0.1526 & 0.1779 & 0.1810 & 0.1765 & 0.2055 & 0.1883 & 0.1831 & 0.1829 & 0.1773 & 0.1726 & 0.1990 & 0.1607 & 0.04 & 0.169 \\
\hline 0.0615 & 0.067 & 0616 & .0630 & 0.0753 & 1780 & 0.755 & 0700 & 0.0667 & 0.0604 & 0.0642 & 0.0573 & 0623 & .0569 & 0.0610 & 0.0591 & 0.0639 & .0663 & 0.0682 & 0.065 & 0.0629 & 0.0653 & 0.0458 & 0.0535 & 0.0624 & 0.0634 & 0.0618 & 0.0720 & 0.0660 & 0.0642 & 0.064 & 0.0621 & 0.0605 & 0.0697 & 0.05 & 0.0 & $0.05 \%$ \\
\hline 0.0562 & 0.073 & .0563 & 0.0576 & 0.0688 & 0713 & 0690 & 0640 & 0610 & 0.0552 & 0.0587 & 1.0524 & 0.0569 & 0.0520 & 0.0558 & 0.0540 & 0.0584 & 0.0606 & 0.0623 & 0.0599 & 0.0575 & 0.0597 & 0.0419 & 0.0489 & 0.0570 & 0.0580 & 0.0565 & 0.0658 & 0.0603 & 0.0587 & 0.0586 & 0.0568 & 0.0553 & & 005 & 0.01 & 0.054 \\
\hline 0.0820 & 0836 & .0822 & 0.0841 & 0.1005 & 1040 & 1008 & 0934 & 0.0890 & 0.0806 & 0.0857 & 0.0765 & 0.0831 & 0.0759 & 0.0815 & 0.0789 & 0.0853 & 0.0885 & 0.0910 & 0.0874 & 0.0840 & 0.0871 & 0.0611 & 0.0714 & 0.0832 & 0.0846 & 0.0825 & 0.0961 & 0.0880 & 0.0856 & 0.0855 & 0.0829 & 0.0807 & 01030 & 0.075 & 0.011 & 0.079 \\
\hline 0.0840 & 0857 & .0842 & 0.0862 & 0.1029 & 1066 & 1032 & 0957 & 0.912 & 0.0826 & 0.0878 & 0.0783 & .0851 & 0.077 & 0.0834 & 0.0808 & 0.0874 & 0.0906 & 0.0932 & 0.0896 & 0.0860 & 0.0892 & 0.0626 & 0.0731 & 0.0852 & 0.0867 & 0.0845 & 0.0984 & 0.0902 & 0.0877 & 0.0876 & 0.0849 & 0.0827 & 0.0953 & 0.077 & 0.020 & 0.081 \\
\hline 0.0400 & 0408 & 401 & 0411 & 0.040 & 1508 & 0492 & 0456 & 0435 & 0.0394 & 0.0418 & 1.0373 & 0.045 & 0.0370 & 0.0398 & 0.0385 & 0.0416 & 0,1327 & 0.0444 & 0.047 & 0.0410 & 0.0425 & 0.0298 & 0.0348 & 0.0406 & 0.0413 & 0.0403 & 0.0469 & 0.0430 & 0018 & 0.0417 & 0.0405 & 0.0394 & 0.0454 & 0367 & 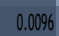 & 0.038 \\
\hline 0.0555 & & & & & & & & & & & & & & & & & & & 1591 & 0.0 & & & & & 0.0572 & 0.1 & & 0595 & & & 0.6 & & & & & .053 \\
\hline 0.0443 & & & & & & & & & & & & & & & & & & & & 0.6 & & & & & 0.0 & 0.6 & & 0.0476 & & & 0.6 & & & 4060 & Uive & 0.042 \\
\hline 0.073 & & & & & & & & & 0.0721 & & & & & & & & & & & 0.0 & & & & & 0.0756 & & & 0.0787 & & & 0.0741 & & & 0672 & 0.017 & 0.070 \\
\hline 0.0677 & & & & & & & & & & & & & & & & & & & & & & & & & & & & 00726 & & & 0684 & 0.067 & & .062 & 0.016 & 0.065 \\
\hline 0.1264 & 1289 & 267 & 296 & 0.1548 & 1603 & 1553 & 1439 & 372 & 1243 & 0.1320 & 1778 & 0.1280 & . 1170 & 01255 & 0.1215 & 0.1314 & 1363 & 0.1402 & 0.1348 & 0.1294 & 0.1343 & 0.0942 & 0.1100 & 0.1282 & 0.1304 & 0.1272 & 0.1481 & 0.1357 & 13119 & 0.1318 & 0.1278 & 0.1244 & 0.1434 & 0.1158 & 0.0301 & 0.122 \\
\hline 0.3303 & 3368 & 3309 & 3387 & 0.4044 & 4488 & 4057 & 3760 & 3584 & 3247 & 0.3450 & 3078 & 0.3345 & 0.3056 & 03780 & 0.3175 & 0.3434 & 3562 & 0.3663 & 0.3521 & 0.3380 & 0.3508 & 0.2460 & 0.2873 & 0.3350 & 0.3407 & 0.3323 & 0.3869 & 0.3544 & 0.3447 & 0.3443 & 0.3338 & 0.3249 & 0.3746 & 0.3025 & 0.079 & 0.319 \\
\hline 0.0728 & 772. & 729 & 747 . & 0.0891 & 5923 & 0894 & & 790 & 0.0716 & 0.0760 & 0679 & 0737 & 0674 & 0.0723 & 0.0 & 0.0757 & & 0.0807 & 0.0776 & 0.0 & 0.0 & 0.0542 & 0.0633 & 0.0738 & 0.0751 & 0.0732 & & 0.0781 & 0.0 & 0.07 & 0.0736 & 0.07 & & 0.066 & 001 & 0.070 \\
\hline 0.1705 & & & & & & & & & & & & & & & & & & & & & & & & & 0.1 & & & & & & & & & & & .164 \\
\hline 0.1752 & & & & & & & & & & & & & & & & & & & & & & & & & & & & & & & & & & & & 0.169 \\
\hline 0.1678 & & 1681 & & 0.2055 & 0.2128 & & & & 0.1649 & 0.1753 & & & 1.552 & 0.1 & 0.1 & & & & & 0.1 & 0.1 & & 0.1459 & 702 & 0.173 & 0.1688 & 0.1 & 0.1801 & 1751 & 0.174 & 0.1696 & & & 1.537 & .040 & 0.162 \\
\hline 0.3037 & 0.3097 & 3043 & 115 & 0.3719 & 3852 & 3731 & 0.3458 & 13296 & 0.2986 & 0.3172 & 2831 & 0.3076 & 0.2810 & 0.3016 & 0.2920 & 0.3158 & 0.3276 & 0.3369 & 0.3238 & 0.3109 & 0.3226 & 0.2262 & 0.2642 & 0.3081 & 0.3133 & 0.3056 & 0.3558 & 0.3259 & 0.3170 & 0.3166 & 0.3070 & 0.2988 & 3444 & 0.2782 & 0.0727 & 0.293 \\
\hline 0.1349 & 0.1376 & 0.1352 & 0.1383 & 0.1652 & 0.1711 & 0.1657 & 0.1536 & 0.1464 & 0.1326 & 0.1409 & 0.1257 & 0.1366 & 0.1248 & 0.1340 & 0.1297 & 0.1403 & 0.1455 & 0.1446 & 0.1438 & 0.1381 & 0.1433 & 0.1005 & 0.1173 & 0.1368 & 0.1391 & 0.1357 & 0.1580 & 0.1448 & 0.1408 & 0.1406 & 0.1363 & 0.1327 & 0.1530 & 0.1236 & 0.0323 & 0.130 \\
\hline 0.0375 & 0.0382 & 0.0376 & 0.0385 & 0.0459 & 0.0476 & 0.0461 & 0.0427 & 0.0407 & 0.0369 & 0.0392 & 0.0350 & 0.0380 & 0.0347 & 0.0372 & 0.0360 & 0.0390 & 0.0404 & 0.0416 & 0.0400 & 0.0384 & 0.0398 & 0.0279 & 0.0326 & 0.0380 & 0.0387 & 0.0377 & 0.0439 & 0.0402 & 0.0391 & 0.0391 & 0.0379 & 0.0369 & 0.0425 & 0.0343 & 0.0090 & 0.036 \\
\hline 0.2122 & 164 & $\{127$ & & 599 & 691 & 107 & 416 & & & 0.2217 & 0.1978 & 0.2149 & 964 & & & 0.2207 & 899 & 2354 & 0.2633 & 0.2172 & 254 & 0.1581 & 0.1846 & 0.2153 & 0.2189 & 0.2135 & 0.2486 & 0.2278 & 0.2215 & 0.2213 & 0.2145 & 0.2088 & 0.2407 & 0.1944 & 0.0508 & 0.205 \\
\hline
\end{tabular}




\section{Post-cluster economic landscape for the NWP}

\begin{tabular}{|c|c|c|c|c|c|c|c|c|c|c|c|c|c|c|c|c|c|c|c|c|c|c|c|c|c|c|c|c|c|c|c|c|c|c|c|c|}
\hline & 2 & & 4 & b & 0 & & & & 10 & & & & 14 & & & & & & & & & & & & & & & & & & & & & & & \\
\hline 0.2916 & 0.2913 & 0.2866 & 0.2943 & 0.3539 & 0.3600 & 0.3555 & 0.3295 & 0.3135 & 0.2821 & 0.2883 & 0.2598 & 0.2924 & 0.2670 & 0.2845 & 0.2759 & 0.2989 & 0.3133 & 0.3201 & 0.3075 & 0.3024 & 0.3122 & 0.2528 & 0.2409 & 0.2889 & 0.2966 & 0.2893 & 0.3383 & 0.3109 & 0.3003 & 0.3009 & 0.3160 & 0.2842 & 0.3269 & 0.2636 & 0.0693 & 1775 \\
\hline 0.0743 & 742 & 730 & 1750 & 0.0902 & 0.0940 & 0.0906 & 0.0839 & 0.0799 & 0.0719 & 760 & 1662 & 0.0745 & 0.0680 & 725 & 703 & 0.0761 & 0.0798 & 0.0815 & 783 & 0.0770 & 0.0795 & 0.0644 & 0.0614 & 736 & 0.0755 & 0.0737 & 0.0862 & 0.0792 & 0765 & 1.0767 & 0.0805 & 0.0724 & 0833 & 0671 & & 0707 \\
\hline 0751 & 0751 & 0.0739 & 7758 & 9912 & 9951 & 0916 & 0.0849 & 0.0808 & 0727 & 769 & 0670 & 0.0753 & 0.0688 & 733 & 0711 & .0770 & 0.0807 & 0.0825 & 792 & 0779 & 10805 & 0.0652 & 0.0621 & 775 & 0764 & 0.0745 & 0.0872 & 0.0801 & 0774 & 10775 & 0.0814 & 0.0732 & 0842 & .0679 & 0178 & . \\
\hline 0.1106 & 0.1105 & 0.1087 & 11116 & 0.1342 & 0.1399 & 0.1348 & 0.1250 & 0.1189 & 0.1070 & 0.1131 & 0.0985 & 0.1109 & 0.1013 & 0.1079 & 0.1046 & 0.1134 & 0.1188 & 0.1214 & 1166 & 0.1147 & 0.1184 & 0.0959 & 0.0914 & $0.10 \%$ & 0.1125 & 0.1097 & 0.1283 & 0.1179 & 0.1139 & 0.1141 & 0.1198 & 0.1078 & 1240 & 1000 & 0263 & 1052 \\
\hline 0.0744 & 0743 & 0.0731 & 0.0751 & 0903 & .041 & 10907 & 0.0841 & 0.0800 & 0.0720 & 0.0761 & 0.0663 & 0.0746 & 0.0681 & 0.0726 & 0.0704 & 0.0762 & 0.0799 & 0.0816 & 0.0784 & 0.0771 & 0.0796 & 0.0645 & 0.0615 & 0737 & 0.0756 & 0.0738 & 0.0863 & 0.0793 & 0.0766 & 0.0768 & 0.0806 & 0.0725 & 0.0834 & 0.062 & 0177 & 0.070 \\
\hline 0.1506 & 504 & 480 & 1519 & 827 & 0.1905 & 335 & 0.1701 & 0.1618 & 1.1456 & 540 & 1341 & 0.1510 & 0.1379 & 0.1469 & 1424 & 0.1543 & 0.1618 & 0.1653 & 0.1587 & 0.1561 & 0.1612 & 305 & 0.1244 & 492 & 0.1531 & 0.1493 & 0.1747 & 0.1605 & 1550 & 0.1554 & 0.1631 & 0.1467 & 1688 & 1361 & .0358 & 0.143 \\
\hline 0.1081 & 0.1080 & 063 & 991 & 0.1312 & 0.1368 & 0.1318 & 0.1222 & 0.1162 & 0.1046 & 0.1106 & 0.0963 & 0.1084 & 0.0990 & 054 & 0.1023 & 0.1108 & 0.1161 & 0.1186 & 140 & 0.1121 & 0.1157 & 0.0937 & 0.0893 & 071 & 0.1099 & 0.1072 & 0.1254 & 0.1153 & 1113 & 0.1115 & 0.1171 & 0.1053 & 1212 & 977 & & .102 \\
\hline 0.085 & 853 & 0839 & 0.0862 & 036 & 1080 & 1041 & 0.0965 & 0.0918 & 0.0826 & 0.0873 & 0761 & 0.0856 & 0.0782 & 0.0833 & 0808 & 0.0875 & 0.0917 & 0.0937 & 9900 & 0.0886 & 0.0914 & 0.0740 & 0.0705 & 0.0846 & 0.0868 & 0.0847 & 0.0991 & 0.0910 & 0.0879 & 0.0881 & 0.0225 & 0.0832 & 0.0957 & 0.0772 & 0201 & .081 \\
\hline 0.0771 & 0.0770 & 0.0758 & 0.0778 & 0936 & 0.0976 & 0.0940 & 0.0871 & 0.0829 & 0.0746 & 0.0789 & 0.0687 & 0.0773 & 0.0706 & 0.0752 & 0.0729 & 0.0790 & 0.0829 & 0.0846 & 0.0813 & 0.0800 & 0.0826 & 0.0669 & 0.0637 & 0.0764 & 0.0784 & 0.0765 & 0.0895 & 0.0822 & 0.0794 & 0.0776 & 0.0836 & 0.0751 & 0.0864 & 0697 & 0183 & 0.073 \\
\hline 0.0688 & 0.0688 & 0.0677 & 0.0695 & 0.0835 & 0.0871 & 0.0839 & 0.0778 & 0.0740 & 0.0666 & 0.0704 & 0.0613 & 0.0690 & 0.0630 & 0.0671 & 0.0651 & 0.0706 & 0.0740 & 0.0756 & 0.0726 & 0.0714 & 0.0737 & 0.0597 & 0.0569 & 0.0682 & 0.0700 & 0.0683 & 0.0799 & 0.0734 & 0.0709 & 0.0710 & 0.0746 & 0.0671 & 0.0772 & 0.0622 & 0164 & 0.065 \\
\hline 0.0487 & 0.0487 & 0.0479 & 0492 & 0591 & 0.0617 & 0.0594 & 0.0551 & 0.0524 & 0.0471 & 0.0498 & 0434 & 0.0489 & 0.046 & 0.0475 & 0461 & 0.0499 & 0.0524 & 0.0535 & 0.0514 & 0.0505 & 0.0522 & 0.0423 & 0.0403 & 0.0483 & 0.0496 & 0.0483 & 0.0565 & 0.0520 & 0.0502 & 0.0503 & 0.0528 & 0.0475 & 0.0546 & 0.040 & .0116 & 1.046 \\
\hline 0.0788 & 0.0787 & 0.0774 & 0.0795 & 0.0956 & 0.0997 & 0.0960 & 0.0890 & 0.0847 & 0.0762 & 0.0806 & 0.0702 & 0.0790 & 0.0721 & 0.0768 & 0.0745 & 0.0808 & 0.0846 & 0.0865 & 0.0831 & 0.0817 & 0.0843 & 0.0683 & 0.0651 & 0.0780 & 0.0801 & 0.0781 & 0.0914 & 0.0840 & 0.0811 & 0.0813 & 0.0854 & 0.0768 & 0.0883 & 0.0712 & .0187 & 0.075 \\
\hline 0.0625 & 0624 & .0614 & 0.0630 & 0758 & 0.070 & 0.0761 & 0.0706 & 0.0671 & 0.0604 & 0.0639 & 0.057 & 0.0626 & 0.0572 & 0.0609 & 0.0591 & 0.0640 & 0.0671 & 0.0686 & 0.0659 & 0.0648 & 0.0669 & 0.0542 & 0.0516 & 0.0619 & 0.0635 & 0.0620 & 0.0725 & 0.0666 & 0.0643 & 0.0645 & 0.0677 & 0.0609 & 0.0700 & 0.0565 & .014 & 0.059 \\
\hline 0.0434 & 0.0433 & 0.0427 & 0.0438 & 0.0527 & 0.0549 & 0.0529 & 0.0490 & 0.0466 & 0.0420 & 0.0444 & .0387 & 0.0435 & 0.0397 & 0.0423 & 0.0411 & 0.0455 & 0.0466 & 0.0476 & 0.0488 & 0.0450 & 0.0465 & 0.0376 & 0.0359 & 0.0430 & 0.044 & 0.0430 & 0.0503 & 0.0463 & 0.0447 & 0.048 & 0.0470 & 0.0423 & 0.0486 & 0.0392 & .010 & 1.041 \\
\hline 0.1562 & 0.1560 & 0.1535 & 0.1576 & 0.1896 & 0.1976 & 0.1904 & 0.1765 & 0.1679 & 0.1511 & 0.1597 & 0.1392 & 0.1566 & 0.1430 & 0.1524 & 0.1478 & 0.1601 & 0.1678 & 0.1714 & 0.1647 & 0.1620 & 0.1672 & 0.1354 & 0.1291 & 0.1547 & 0.1589 & 0.1549 & 0.1812 & 0.1665 & 0.1609 & 0.1612 & 0.1692 & 0.1522 & 0.1751 & 0.1412 & 0.0371 & 0.148 \\
\hline 0.0736 & .0735 & .0723 & 0.0742 & 0893 & .0931 & 0.087 & 0.0831 & 0.079 & 1.0712 & 0752 & 0655 & 0.0738 & 0.0674 & 0718 & $06 \%$ & 1.0754 & 0.0791 & 0.0808 & 0.0776 & 0.0763 & 0.0788 & 0.0638 & 0.0608 & .0729 & 0.0748 & 0.0730 & 0.0854 & 0.0784 & 0.0758 & 0.0759 & 0.0797 & 0.0717 & 0.0825 & 0.066 & 0.017 & 0.070 \\
\hline 0.1123 & 0.1122 & 0.1104 & 0.1133 & 0.1363 & 0.1421 & 0.1369 & 0.1269 & 0.1207 & 0.1086 & 0.1148 & 0.1000 & 0.1126 & 0.1028 & 0.1095 & 0.1062 & 0.1151 & 0.1207 & 0.1233 & 0.1184 & 0.1165 & 0.1202 & 0.0974 & 0.0928 & 0.11113 & 0.1142 & 0.1114 & 0.1303 & 0.1197 & 0.1156 & 0.1159 & 0.1217 & 0.1094 & 0.1259 & 0.1015 & 0.0267 & 0.106 \\
\hline 0.1820 & 0.1818 & 0.1789 & 0.1837 & 0.2209 & 0.2303 & 0.2219 & 0.2057 & 0.1957 & 0.1761 & 0.1862 & .1622 & 0.1825 & 0.1667 & 0.1776 & 0.1722 & 0.1866 & 0.1956 & 0.1998 & 0.1919 & 0.1888 & 0.1949 & 0.1578 & 0.1504 & 0.1803 & 0.1851 & 0.1806 & 0.2112 & 0.1941 & 0.8875 & 0.1878 & 0.1972 & 0.1774 & 0.2040 & .1645 & 0.0432 & 0.173 \\
\hline 0.0621 & 0.0620 & 0.0611 & 0.0627 & 0754 & .0786 & 0.0757 & 0.0702 & 0.0668 & 0.0601 & 0635 & .0553 & 0.0623 & 0.0569 & .0606 & 0588 & 0.0637 & 0.0667 & 0.0682 & 0.0655 & 0.0644 & 0.0665 & 0.0539 & 0.0513 & .0615 & 0.0632 & 0.0616 & 0.0721 & 0.0662 & 0.0640 & 0.0641 & 0.0673 & 0.0605 & .0696 & 056 & 014 & 0.059 \\
\hline 0.0583 & 0.0582 & 0.0573 & 0.0588 & 0.0708 & 0.0738 & 0.0711 & 0.0659 & 0.0627 & 0.0564 & 0.0596 & 0.0520 & 0.0585 & 0.0534 & 0.0569 & 0.0552 & 0.0598 & 0.0627 & 0.0640 & 0.0615 & 0.0605 & 0.0624 & 0.0506 & 0.0482 & 0.0578 & 0.0593 & 0.0578 & 0.0677 & 0.0622 & 0.0601 & 0.0602 & 0.0632 & 0.0568 & 0.0654 & 0.0527 & 0.0139 & 0.0555 \\
\hline 0.0663 & 0.0662 & 0.0651 & 0.0669 & 0804 & 0.0838 & 0.0808 & 0.0749 & 0.0712 & 0.0641 & 0.0678 & .0590 & 0.0664 & 0.0607 & .0646 & 0627 & 0.0679 & 0.0712 & 0.0727 & 0.0699 & 0.0687 & 0.0709 & 0.0574 & 0.0547 & .0656 & 0.0674 & 0.0657 & 0.0769 & 0.0706 & 0.0682 & 0.0684 & 0.0718 & 0.0646 & .0743 & 0.0599 & .015 & 0.063 \\
\hline 0.0865 & 0.0864 & 0.0850 & 0.0873 & 0.1050 & 0.1094 & 0.1054 & 0.0977 & 0.0930 & 0.0837 & 0.0885 & 0.0771 & 0.0867 & 0.0792 & 0.0844 & 0.0818 & 0.0887 & 0.0229 & 0.0449 & 0.0912 & 0.0897 & 0.026 & 0.0750 & 0.0715 & 0.0857 & 0.0880 & 0.0858 & 0.1004 & 0.0922 & 0.0891 & 0.0893 & 0.0937 & 0.0843 & 0.0970 & 0.0782 & 0.0205 & 0.0823 \\
\hline 0.0394 & 0.0393 & 0.0387 & 0.0397 & 0.0478 & 0.0498 & 0.0480 & 0.0445 & 0.0423 & 0.0381 & 0.0403 & 0.0351 & 0.0395 & 0.0360 & 0.0384 & 0.0372 & 0.0403 & 0.0423 & 0.0432 & 0.0415 & 0.0408 & 0.0421 & 0.0341 & 0.0325 & 0.0390 & 0.0400 & 0.0390 & 0.0457 & 0.0420 & 0.0405 & 0.0406 & 0.0477 & 0.0384 & 0.0441 & 0.0356 & 0.0094 & 0.0375 \\
\hline 0.0565 & 0.0565 & 0.0556 & 0.0570 & 0686 & 0.0715 & 0.0689 & 0.0639 & 0.0608 & 0.0547 & 0.0578 & 0.0504 & 0.0567 & 0.0518 & 0.0551 & 0.0535 & 0.0579 & 0.0607 & 0.0620 & $0.05 \%$ & 0.0586 & 0.0605 & 0.0490 & 0.0467 & 0.0560 & 0.0575 & 0.0561 & 0.0656 & 0.0603 & 0.0582 & 0.0583 & 0.0612 & 0.0551 & 0.0634 & 0.051 & 0.013 & 0.053 \\
\hline 0.0450 & 0.0449 & 0.042 & 0.0454 & 0546 & 0.0569 & 0.0548 & 0.0508 & 0.0883 & 0.0455 & 0.0460 & 0.0401 & 0.0451 & 0.0412 & 0.0439 & 0.0425 & 0.0461 & 0.0483 & 0.0494 & 0.0474 & 0.0466 & 0.0482 & 0.0390 & 0.0372 & 0.046 & 0.0457 & 0.0446 & 0.0522 & 0.0480 & 0.0463 & 0.0464 & 0.0487 & 0.0438 & 0504 & 0407 & 0.0107 & 0.0428 \\
\hline 0.0787 & 0.0786 & 774 & 794 & 0956 & .0996 & 960 & 0.0890 & 0.0846 & 0762 & 805 & 0701 & 0.0789 & 0.0721 & (668 & 0745 & 0.0807 & 0.0846 & 0.0864 & 0.0830 & 0.0816 & 0.0843 & 0.0683 & 0.0650 & .0780 & 0.0801 & 0.0781 & 0.0913 & 0.0839 & 0.0811 & 0.0812 & 0.0853 & 0.0767 & 0.0882 & 0.0712 & 0.0187 & 0.0749 \\
\hline 0.0711 & 0.0711 & 0.0699 & 0.0718 & 0863 & 0.090 & 0.0867 & 0.0804 & 0.0765 & 0.0688 & 0.0728 & 0.0634 & 0.0713 & 0.0651 & 0.0694 & 0.0673 & 0.0729 & 0.0764 & 0.0781 & 0.0750 & 0.0738 & 0.0762 & 0.0617 & 0.0588 & 0.0705 & 0.0723 & 0.0706 & 0.0825 & 0.0758 & 0.0733 & 0.0734 & 0.0771 & 0.0693 & 0.0797 & 0.0643 & 0.016 & 0.0677 \\
\hline 0.1265 & 0.1263 & 243 & 0.1276 & 1535 & 1600 & 542 & 0.1429 & 0.1359 & 0.1223 & 0.1223 & .1127 & 0.1268 & 0.1158 & 0.1234 & 0.1196 & 0.1296 & 0.1359 & 0.1388 & 0.1333 & 0.1312 & 0.1354 & 0.1097 & 0.1045 & 0.1253 & 0.1286 & 0.1254 & 0.1467 & 0.1348 & 0.1302 & 0.1305 & 0.1370 & 0.1232 & 0.1418 & 0.1143 & 0.0300 & 0.1203 \\
\hline 0.3369 & 0.3365 & 0.3311 & 0.3399 & 0.4889 & 0.4262 & 0.4107 & 0.3807 & 0.3621 & 0.3259 & 0.345 & 0.3001 & 0.3378 & 0.3085 & 0.3286 & 0.3187 & 0.3453 & 0.3620 & 0.3698 & 0.3552 & 0.3444 & 0.3607 & 0.2221 & 0.2783 & 0.3338 & 0.3426 & 0.3341 & 0.3008 & 0.3592 & 0.3469 & 0.3476 & 0.3650 & 0.3283 & 0.3776 & 0.3045 & 0.0800 & 0.320 \\
\hline 0.0704 & 0.0703 & 692 & 0.0710 & 0.0854 & 0.0890 & 0.0858 & 0.0795 & 0.0756 & 0.0681 & 0.0720 & 0.0627 & 0.0705 & 0.0644 & 0.0686 & 0.0666 & 0.0721 & 0.0756 & 0.0772 & 0.0742 & 0.0730 & 0.0753 & 0.0610 & 0.0581 & 0.0697 & 0.0716 & 0.0698 & 0.0816 & 0.0750 & 0.0725 & 0.0726 & 0.0762 & 0.0686 & 0789 & & 0.0167 & 0.066 \\
\hline 0.1677 & 0.1675 & 648 & 0.1692 & 0.2035 & 0.2122 & 0.2044 & 0.1895 & 0.1803 & 0.1622 & 1715 & 0.1444 & 0.1681 & 0.1536 & 0.1636 & 0.1586 & 0.1719 & 0.1802 & 0.1841 & 0.1768 & 0.1739 & 0.1795 & 0.1454 & 0.1385 & 0.1661 & 0.1705 & 0.1663 & 0.1945 & 0.1788 & 0.1727 & 0.1730 & 0.1817 & 0.1634 & 0.1880 & 0.1516 & 0.0398 & 0.1596 \\
\hline 0.1783 & 0.1781 & 753 & 0.1800 & 0.2164 & 0.2257 & 74 & 0.2015 & 0.1917 & 0.1725 & 824 & 0.1589 & 0.1788 & 0.1633 & 740 & 0.1687 & 0.1828 & 0.1916 & 0.1958 & 0.1880 & 0.1850 & 0.1909 & 546 & 0.1474 & 0.1767 & 0.1814 & 0.1769 & 0.2069 & 0.1902 & 0.1837 & 0.1840 & 0.1932 & 0.1738 & 1999 & . & 0.0424 & 0.169 \\
\hline 0.1709 & 0.1707 & 680 & 0.1725 & 0.2074 & 0.2163 & 084 & 0.1931 & 0.1837 & 0.1653 & 0.1748 & 1523 & 0.1714 & 0.1565 & 0.1667 & 0.1617 & 0.1752 & 0.1836 & 0.1876 & 0.1802 & 0.1773 & 0.1830 & 0.1482 & 0.1412 & 0.1693 & 0.1738 & 0.1695 & 0.1983 & 0.1822 & 0.1760 & 0.1764 & 0.1852 & 0.1665 & 0.1916 & .1545 & 0.0406 & 1.1626 \\
\hline 0.3170 & 0.3166 & 0.3116 & 0.3198 & 0.3847 & 0.4011 & 0.3864 & 0.3582 & 0.3407 & 0.3067 & 0.3242 & 0.2824 & 0.3178 & 0.2903 & 0.3092 & 0.2999 & 0.3249 & 0.3406 & 0.3479 & 0.3342 & 0.3287 & 0.3394 & 0.2748 & 0.2619 & 0.3140 & 0.3224 & 0.3144 & 0.3678 & 0.3380 & 0.3264 & 0.3271 & 0.3435 & 0.3089 & 0.3553 & 0.2865 & 0.0753 & 0.301 \\
\hline 0.1493 & 0.1491 & 0.1467 & 0.1506 & 0.1812 & 0.1889 & 0.1820 & 0.1687 & 0.1605 & 0.1444 & 0.1527 & 0.1330 & 0.1497 & 0.1367 & 0.1456 & 0.1412 & 0.1530 & 0.1604 & 0.1639 & 0.1574 & 0.1548 & 0.1598 & 0.1224 & 0.1233 & 0.1479 & 0.1518 & 0.1481 & 0.1732 & 0.1592 & 0.1537 & 0.1540 & 0.1618 & 0.1455 & 0.1673 & 1349 & 0.0355 & 142 \\
\hline 0.0379 & 0.0378 & 0.0372 & 0.0382 & 0.0460 & 0.0479 & 0.0462 & 0.0428 & 0.0407 & 0.0366 & 0.0387 & 0.0337 & 0.0380 & 0.0347 & 0.0369 & 0.0358 & 0.0388 & 0.0407 & 0.0416 & 0.0399 & 0.0393 & 0.0406 & 0.0328 & 0.0313 & 0.0375 & 0.0385 & 0.0376 & 0.0439 & 0.0404 & 0.0390 & 0.0391 & 0.0410 & 0.0369 & 0.0425 & 0.0342 & 0.0090 & 0.0360 \\
\hline 0.2172 & 0.2170 & 135 & 1912 & 0.2636 & 0.2748 & 0.2648 & 454 & 0.2335 & 0.2101 & 0.2221 & 0.1935 & 0.2178 & 0.1989 & 0.2119 & 0.2055 & 0.2226 & 0.2334 & 0.2384 & 0.2290 & 0.2252 & 0.2325 & 0.1883 & 0.1795 & 0.2152 & 0.2209 & 0.2154 & 0.2520 & 0.2316 & 0.2237 & 0.2241 & 0.2353 & 0.2116 & 0.2435 & 0.1963 & 0.0516 & 0306 \\
\hline
\end{tabular}


Change from pre- to post-cluster economic landscape

\begin{tabular}{|c|c|c|c|c|c|c|c|c|c|c|c|c|c|c|c|c|c|c|c|c|c|c|c|c|c|c|c|c|c|c|c|c|c|c|c|c|}
\hline & 2 & & & 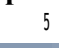 & & & & & & & & & & & & & & & & & & & & & & & & & & & & & & & & \\
\hline 0.0048 & 12 & 007 & & . 0027 & 0.0053 & & 030 & 0022 & 0.0002 & & & 0.0019 & .0017 & & & 0.0007 & 0.0040 & & & 0.0089 & 0.0076 & & 0.0085 & 0.0020 & 0.0007 & & 0.0023 & 0.0031 & & & 0.0261 & 0.0020 & 0.0016 & 0.0009 & & \\
\hline 0.0007 & 0008 & 007 & & 0001 & 0.0007 & & & 000 & 0004 & 0.0008 & 0024 & 0.0000 & 0000 & 1.0006 & 004 & 0.0003 & 0.0005 & 0000 & 0.0001 & 0.0018 & 0.0014 & $00 \%$ & -0.026 & 0.0010 & 0.0003 & 0.0003 & .0000 & 0.0003 & 0.0003 & 0.0000 & 0.0062 & .0000 & 0.0001 & 0.0002 & 0001 & \\
\hline 0.0008 & 007 & 0006 & $\sqrt{4}$ & 002 & 0008 & & 003 & 001 & 0.0004 & $\cdot 0.0008$ & 0.0023 & 001 & 0000 & 0.0005 & 004 & 0.0003 & 006 & 0.0000 & 0.0000 & 0.0018 & 015 & 098 & 0.0026 & -0.0010 & 0.0003 & 0.0003 & out & 0.0003 & 0.0002 & 0.0000 & 0063 & 0.0001 & 0001 & 0002 & 0001 & \\
\hline-0.0817 & 0.0855 & 0839 & 1856 & .1012 & 0.1039 & 013 & .0939 & 0898 & .0820 & $\cdot 0.0877$ & 0.0807 & 0.0838 & 1.0766 & 0.0830 & $\cdot 0.0802$ & 0.0865 & 0.0885 & 0.0918 & 0.0883 & -0.0821 & $\cdot 0.0858$ & 0.0473 & 0.0758 & 0.0854 & 0.0858 & -0.0837 & 0.0669 & $\cdot 0.0884$ & -0.0867 & 0.0863 & 0.0745 & 0.0813 & -0.0941 & 0.0761 & 191 & \\
\hline 0.0071 & 057 & 557 & 061 & 1079 & 0.0088 & & 075 & 1070 & 0058 & 0.0058 & 36 & 0065 & 0059 & 0.0058 & 0.0057 & 0.0063 & 0074 & .0070 & 0.0067 & 0.0083 & 0.0082 & 0.0144 & 0.0029 & 0.0055 & 0.0063 & 0.0061 & 0.0075 & 0.0071 & 0.0064 & 0.0066 & 0.0126 & 0.0063 & 0.0071 & 0.0056 & 0016 & \\
\hline $0.00 \%$ & 067 & 0.0067 & 0.0074 & 101 & 0.0117 & & 009 & .0089 & 0071 & 0.0067 & 0.0027 & 0.0082 & 0074 & 0.0069 & 069 & 0.0078 & 1097 & 0.0089 & 0.0085 & 0.0119 & 0.0115 & 0.0255 & 0.0018 & 0.0062 & 0.0077 & 0.0075 & 0.0095 & 0.0093 & 0.0079 & 0.0084 & 0207 & 0.0080 & 0.0089 & 0.0070 & 10020 & $\infty$ \\
\hline 0.0020 & 0.0002 & 0.0000 & 0.0003 & .0013 & 0.0023 & 015 & .014 & 0.0011 & 0.0003 & $\cdot 0.0002$ & 0.0025 & 0.0010 & 0.0009 & 0.0001 & 0.0003 & 0.0005 & 0.0018 & 0.0010 & 0.0009 & 0.0036 & 0.0031 & 0.0147 & 0.0029 & 0.0005 & 0.0005 & 0.0005 & 0.0012 & 0.0014 & 0.0006 & 0.0010 & 0.0099 & 0.0010 & 0.0009 & 0.0006 & 0.003 & .00 \\
\hline 0.0147 & 132 & 0131 & 136 & 170 & 0.0184 & & 0160 & 0150 & 0131 & 0.0135 & 0.0102 & 0.0140 & 0128 & 0.0131 & 0.0128 & 0.0140 & 0.0155 & 0.0153 & 0.0146 & 0.0162 & 0.0163 & 0.0214 & 0.0090 & 0.0129 & 0.0139 & 0.0136 & 0.0162 & 0.0152 & 0.0141 & 0.0144 & 0.0211 & 0.0136 & 0.0155 & 0.0124 & 0.0034 & 01 \\
\hline 0.0030 & 014 & 0015 & & 018 & .0035 & & 027 & 0024 & 0017 & 0.0014 & 0.0004 & .0022 & .020 & 0.0016 & 0.0017 & 0.0019 & 0.0029 & 0.0024 & 0.0022 & 0.0041 & 0.0038 & 0.0116 & 0.0008 & 0.0012 & 0.0019 & 0.0019 & 0.0026 & 0.0026 & 0.0020 & 0.0023 & 0.080 & 0.0022 & 0.0023 & 0.0018 & .0006 & 00 \\
\hline 0.0018 & 0004 & 0005 & 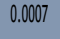 & 014 & 0.0020 & & 0014 & .0012 & 0007 & 0.0004 & 0.0012 & 0.0011 & 0.0010 & 0.0005 & 007 & 0.0008 & 0.0016 & 0.0012 & 0.0011 & 027 & 0.0025 & 0097 & -0.0015 & 0.0002 & 0008 & 0008 & 0.0013 & 0.0014 & 0.0009 & 011 & 0068 & 0.0011 & 0.0011 & 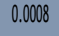 & . 003 & 0 \\
\hline 0.0018 & 0008 & 0009 & 010 & 017 & 0.0021 & & 0016 & 0014 & 0010 & 0.0008 & 0.0003 & .0013 & .0012 & 0.0009 & 0.0010 & 0.0012 & 0.0017 & 0.0014 & 0.0013 & 0.0025 & 0.0023 & 0.0073 & 0.0006 & 0.0007 & 0.0012 & 0.0011 & 0.0016 & 0.0016 & 0.0012 & 0.0014 & 054 & 0.0013 & 0.0014 & 0.0011 & 0.0004 & \\
\hline 0.0035 & 052 & 0050 & & 051 & 0.0046 & & 346 & 046 & 1047 & 0.0054 & 0.0065 & 043 & 040 & .0048 & 046 & 0.0048 & 041 & .0048 & 0.0046 & 0.0025 & 0.0030 & .0070 & 0.0065 & .0 .0054 & 0.0047 & .0046 & 0.050 & 0.0043 & 0.0047 & 0.0045 & & 0.0442 & 0.0030 & 0.004 & . & \\
\hline 0.0027 & 0014 & 0015 & .0017 & 0026 & 0.0032 & 207 & .0025 & .0023 & 0.0017 & 0.0014 & 0.0001 & 0.0021 & 0.0019 & 0.0016 & 0.0016 & 0.0019 & 0.0026 & 0.0022 & 0.0021 & 0.0036 & 0.0034 & $0.00 \%$ & 0.0004 & 0.0012 & 0.0019 & 0.0018 & 0.0024 & 0.0024 & 0.0019 & 0.0021 & 0073 & 0.0020 & 0.0022 & 0.0017 & 0.005 & 00 \\
\hline 0.0009 & 0.0001 & 0.0001 & 0.0002 & 0.0007 & 0.0011 & 08 & 0007 & .0006 & 0.0002 & 0.0000 & 0.0009 & 0.0005 & 0.0005 & 0.0002 & 0.0002 & 0.0003 & 0.0008 & 0.0005 & 0.0005 & 0.0016 & 0.0014 & 0.0060 & $\cdot 0.0011$ & 0.0001 & 0.0003 & 0.0003 & 0.0006 & 0.0007 & 0.0004 & 0.0005 & 0.0041 & 0.0005 & 0.005 & 0.0003 & 0002 & 00 \\
\hline 0.0151 & 0122 & 1122 & 130 & 168 & 0.0188 & & 159 & 148 & 0125 & 0.0124 & 0.0077 & 0.0138 & 125 & 0.0123 & 0.0122 & 0.0135 & 0.0157 & 0.0150 & 0.0143 & 0.0176 & 0.0174 & 0.0304 & 0.0064 & 0.0117 & 0.0134 & 0.0130 & 0.0160 & 0.0152 & 0.0136 & 0.0141 & 0.667 & 0.0134 & 0.0151 & 0.01 & vos & \\
\hline 0.0005 & 1010 & 009 & 1007 & 0002 & 0.0004 & & 0000 & . & 0.006 & 0.0011 & $\cdot 0.0026$ & 0002 & 0002 & 0.0008 & $\cdot 0.0006$ & $\cdot 0.0005$ & 0.0003 & .0003 & 0.0003 & 0.0015 & 0.0012 & 0.0094 & 0.0028 & 0.0012 & 0.0005 & .0 .0005 & 0.0002 & 0.0000 & 0.0003 & 0.0005 & o. & 0.002 & 0.0004 & 0.0004 & .000 & 00 \\
\hline 0.0019 & 1004 & 0002 & 001 & 011 & 0.0021 & 13 & 0012 & 009 & 0001 & $\cdot 0.0004$ & 0.0028 & 0.0008 & 0007 & 0.0001 & 0.0001 & 0.0004 & 0.0016 & 0.0008 & 0.0007 & 0.0035 & 0.0030 & 0.0152 & 0.0032 & 0.0007 & 0.0004 & 0.0003 & 0.0010 & 0.0013 & 0.0005 & 0008 & 101 & 0.0009 & 0.0007 & 0.0004 & 0003 & 00 \\
\hline 0.0066 & 1030 & JII & & 1061 & 0.0079 & & 660 & 053 & UST & 0.0029 & 0.0013 & 049 & 044 & .0034 & 0.0 & 0.0042 & 0064 & .052 & 0.0 & 0.0092 & 0.0086 & 0272 & .0022 & 0.0024 & 0.0042 & & $.035 /$ & 0.0058 & 0.0044 & & & 0.0400 & 0.0031 & & & \\
\hline 0.0006 & 0006 & 005 & & 001 & 0.0006 & & & 001 & 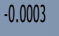 & 0.0007 & 0.0020 & 000 & 000 & 0.003 & 0.0003 & 0.0002 & 1.0004 & 0.000 & 0.000 & 0.0015 & 0.0012 & .0081 & 0.0022 & 0.0008 & 0.0002 & 0.0002 & 0.0000 & 0.0003 & 0.0002 & 0.0000 & OUSL & 0.0001 & 0.0001 & 0.002 & .0001 & \\
\hline 0.0021 & 0009 & 010 & 012 & 019 & 0.0025 & & 019 & 017 & 0012 & 0.0009 & -0.0004 & 015 & 014 & 0.0011 & 0.0011 & 0.0013 & 0020 & 0.0017 & 0.0016 & 0.0030 & 0.0027 & 0.0087 & 0.0007 & 0.0008 & 0.0013 & 0.0013 & 0.0018 & 0.0019 & 0.0014 & 0.0016 & 0064 & 0.0015 & 0.0016 & 0.0012 & 0.004 & 00 \\
\hline 0.0158 & 175 & & & 200 & 10202 & & & & & 179 & 0.0174 & 166 & 52 & & 62 & 0.0174 & 73 & 183 & 0.01 & 0.0152 & -0.0162 & .0037 & -0.0166 & -0.0176 & & & 0192 & 0.017 & 0.01 & & & 0.061 & 0.01 & & & \\
\hline 0.0025 & 0007 & & & 021 & 0.0029 & & 221 & 0018 & 011 & 0.0007 & 0.0013 & 016 & 0015 & 0.0004 & 0.0011 & 0.0013 & 0.0023 & .0017 & 0.0016 & 0.0037 & 0.0034 & .0124 & 0.0016 & 0.0005 & 0.0013 & 0.0013 & 0.0019 & 0.002 & 0.0014 & 0.0011 & 0.0000 & 0.0016 & 0.0017 & 0.00 & .0004 & \\
\hline -0.0007 & 0015 & 114 & & 013 & 0.0010 & & 011 & 0011 & 0013 & 0.0016 & -0.0022 & 011 & 010 & 0.0014 & $\cdot 0.0012$ & -0.0013 & 0009 & 0012 & 0.0012 & $\cdot 0.0002$ & 0.0004 & 0.0043 & -0.0023 & 0.0016 & 0.0013 & $\cdot 0.0012$ & $\cdot 0.0012$ & $\cdot 0.0010$ & 0.0012 & .0 .0011 & 0022 & -0.0010 & 0.0013 & 0.001 & .0002 & 00 \\
\hline 0.0011 & 001 & & & & 0012 & & & & & 0001 & 0013 & & & & 002 & 0.0003 & 109 & 0005 & 0.0005 & 019 & 0.0016 & 0.0077 & 0.0015 & -0.0002 & 0.0003 & 0003 & 0.000 & 0.0008 & 0.0003 & 0005 & 052 & 0.0005 & 0.0005 & 0.0003 & 拉 & . \\
\hline 0.0006 & 1003 & & & 003 & 0.0007 & & & 002 & 001 & 0.0003 & -0.0013 & 002 & 002 & $0 L$ & $\cdot 0.0$ & 0.0000 & 005 & 0.0002 & 0.0002 & 0.0013 & 0.0011 & 0.0060 & -0.0014 & 0.0004 & 0.0000 & 0.0000 & 0.0002 & 0.0004 & 0.0000 & 0.0002 & .0037 & 0.0002 & 0.0001 & 0.00 & 0000 & \\
\hline 0.0054 & 0039 & & & 057 & 0.0066 & & & 050 & 041 & 0.0039 & 0.0018 & 047 & 0042 & 0.0040 & 0.0040 & 0.0045 & 0055 & 0.0051 & 0.0048 & 0.0066 & 0.0064 & 0.0136 & 0.0013 & 0.0036 & 0.0044 & 0.0043 & 0.0054 & 0.0052 & 0.0045 & 0.0048 & 0.0112 & 0.0046 & 0.0051 & 0.0040 & 0.0012 & .00 \\
\hline 0.0035 & 21 & & & & & & & & & & 0.0 & & & & & & & 30 & 0.0 & 0.4 & 043 & 171 & 0.0001 & 0.0019 & 0.0 & 025 & 0.035 & 0.0032 & 0.0 & 1029 & 0087 & 0.0028 & 0.0030 & 0.0023 & .000/ & 00 \\
\hline 0.0001 & 026 & & & & 0.0003 & & & & & & & & & & & & & & $\cdot 0.0$ & 0.0018 & 0.0012 & 0.0155 & 0.0055 & 0.0029 & 0.0018 & .0 .0017 & .0014 & $\cdot 0.0008$ & 0.0017 & 0.0013 & .0093 & 0.0011 & .0 .0016 & 0.00 & 0.002 & 00 \\
\hline 0.0066 & 0003 & & & 044 & 0.0074 & & 447 & & 0012 & 0.0004 & 0.0077 & 033 & 0029 & 0.0006 & 0.0012 & 0.0019 & 0.0058 & 0.0034 & 0.0031 & 0.0113 & 0.0099 & 0.0461 & 0.0089 & -0.0012 & 0.0020 & 0.0019 & 0.0039 & 0.0048 & 0.0022 & 0.0033 & 0.0312 & 0.034 & 0.0031 & 0.0020 & 0.0011 & 100 \\
\hline 0.0024 & 040 & & & & 033 & & & & & & & & & & & 036 & & & & & 020 & 0.0068 & -0.0052 & -0.0041 & & & 0.00 & $\cdot 0.01$ & & & (U), & 0.00 & 0.0037 & & .0001 & \\
\hline-0.0028 & 1064 & & & & 0.0041 & 050 & & & & $\cdot 0.0066$ & $\cdot 0.0095$ & & 042 & & 533 & 0.0034 & & 031 & 0.0050 & $\cdot 0.0006$ & 0.0016 & 0.0184 & 0.0098 & 0.0068 & -0.0053 & $\cdot 0.0052$ & .0532 & $\cdot 0.0042$ & 0.0033 & -0.0047 & 0094 & .0 .0044 & .0 .0054 & 0.0046 & .0010 & 00. \\
\hline 0.0031 & 1005 & & & & 0.0035 & & & & & 0.0006 & 0.0044 & 014 & 012 & & 0.0003 & 0.0007 & 027 & 0.0014 & 0.0013 & 0.0056 & 0.0049 & 0.0241 & 0.0050 & -0.0010 & 0.0007 & 0.0006 & 0.0017 & 0.0021 & 0.0008 & 0.0014 & 0.0162 & 0.0014 & 0.0012 & 0.0007 & 0.0005 & 0.00 \\
\hline 0.0031 & 0.0004 & & & 20 & 0.0035 & & & & & $\cdot 0.00$ & 0.0 & 14 & & & 0.0 & 008 & 0.0027 & & 0.0 & 0.0 & 0.0048 & 0.0232 & -0.0047 & 0.0009 & 0.0008 & 0.0007 & 0.0017 & 0.0022 & 0.0009 & 0.0014 & 年 & 0.0015 & 0.0013 & 0.0008 & 0003 & \\
\hline 0.0133 & 1069 & 072 & & & 0.0159 & & & & & 0.00 & $\cdot 0.0007$ & 102 & 093 & & 0.0 & 0.0091 & 130 & & 04 & 179 & 0.0168 & 0.0486 & 0.0023 & 0.0060 & 0.0091 & 0.0089 & 0.0120 & 0.0120 & 0.0094 & .0105 & 0365 & 0.0101 & 0.0109 & 0.0083 & 0027 & 00 \\
\hline 0.0144 & 0.0116 & 16 & & 160 & 0.0178 & & 51 & 0.0141 & & 0.0118 & 0.0073 & 0.0131 & 0.0119 & 0.0117 & 0.0115 & 0.0128 & 0.0149 & 0.0142 & 0.0136 & 0.0167 & 0.0166 & 0.0289 & 0.0060 & 0.0111 & 0.0127 & 0.0123 & 0.0152 & 0.0144 & 0.0129 & 0.0134 & 0.0254 & 0.0128 & 0.0143 & 0.0114 & 0.0032 & .01 \\
\hline 0.0004 & 0.0004 & & & & & & & & & & & & & & & & & & & & 107 & 0.0049 & $\cdot 0.0$ & 0.0 & & 0.0002 & & & & & & .00 & & 0.0001 & 年 & \\
\hline 0.0049 & 0.0005 & & & 0.0031 & 0.0057 & & & 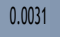 & 0.011 & & 年, & & 0.0012 & 0.0011 & & & 0.043 & 0.030 & & & $0.00 / 1$ & 0.0302 & .0 .0521 & & 0.0020 & 0.0019 & 0.0034 & 0.0038 & $0.002 L$ & & 0.0208 & 0.0029 & 0.0028 & 0.0019 & 0.0000 & \\
\hline & & & & & & & & & & & & & & & & & & & & & & & & & & & & & & & & & & & & \\
\hline
\end{tabular}




\section{NOTES}

